Adv Healthc Mater. 2015 November 18; 4(16): 2408-2422. doi:10.1002/adhm.201500126.

\title{
Recent Advances in Targeted, Self-Assembling Nanoparticles to Address Vascular Damage Due to Atherosclerosis
}

\author{
Eun Ji Chung ${ }^{*}$ and Matthew Tirrell \\ Institute for Molecular Engineering, University of Chicago, 5747 S. Ellis Ave., Chicago, IL, 60637, \\ USA
}

\begin{abstract}
Self-assembling nanoparticles functionalized with targeting moieties have significant potential for atherosclerosis nanomedicine. While self-assembly allows for easy construction (and degradation) of nanoparticles with therapeutic or diagnostic functionality, or both, the targeting agent can direct them to a specific molecular marker within a given stage of the disease. Therefore, supramolecular nanoparticles have been investigated in the last decade as molecular imaging agents or explored as nanocarriers that can decrease the systemic toxicity of drugs by producing accumulation predominantly in specific tissues of interest. In this review, we first describe the pathogenesis of atherosclerosis and the damage caused to vascular tissue, as well as the current diagnostic and treatment options. Then we provide an overview of targeted strategies using self-assembling nanoparticles and include liposomes, high density lipoproteins, protein cages, micelles, proticles, and perfluorocarbon nanoparticles. Finally, we elaborate on and provide an overview of current challenges, limitations, and future applications for personalized medicine in the context of atherosclerosis of self-assembling nanoparticles.
\end{abstract}

\section{Keywords \\ self-assembly; nanoparticle; atherosclerosis; liposome; vascular damage}

\section{Introduction}

Cardiovascular diseases (CVDs) involve the heart and blood vessels, and are the leading causes of deaths globally, approximating 17.3 million deaths per year. In the United States, an estimated 85.6 million American adults ( $>1$ in 3 ) have one or more type of CVD and since 1918, CVD has accounted for more deaths than any other major cause ${ }^{[1]}$. On average, CVD accounts for one death every 40 seconds, totaling 2150 deaths each day (or close to 800,000 per year), and claims more lives each year than cancer. The American Heart Association (AHA) has recently reported that if all forms of CVD were eliminated, life expectancy could rise by almost seven years ${ }^{[1]}$. Given such gravity, the implications of CVD should prompt our attention, as well as inspire our most innovative interventions for diagnostic and therapeutic applications.

*Corresponding Author: Eun Ji Chung, Institute for Molecular Engineering, University of Chicago, 5747 S. Ellis Ave., Chicago, IL, 60637, USA, Tel.: +1-773-702-7063, Fax: +1-773-834-7756, chunge@ uchicago.edu. 


\subsection{Risk Factors ${ }^{[1]}$}

CVDs are complex and multifactorial diseases, making it difficult to clearly define any one risk factor as the most significant as indicated by the $\mathrm{AHA}^{[1]}$. However, lifestyle-related risk factors are considered to be the foremost causes of CVD. Such risk factors include smoking, physical inactivity, poor nutrition/diet, and obesity. Although smoking has declined from $36.4 \%$ in 1997 to $15.7 \%$ in 2013, almost one third of coronary heart disease deaths are attributable to smoking and exposure to secondhand smoke. Also in 2013, the National Health Interview Survey data confirmed that only half of American adults met the current aerobic physical activity guidelines of 150 minutes of moderate physical activity or 75 minutes of vigorous physical activity or an equivalent combination each week. Inadequate nutrition also contributes to the prevalence of CVD and the intake of excess sodium alone attributed to 58,000 CVD deaths per year. Although healthier diets cost modestly more than unhealthful diets, more healthful food-based diet patterns are estimated to cost only on average approximately $\$ 1.50$ more per day. Perhaps obesity could be considered to be one of the more significant risk factors as it predisposes individuals to other major risk factors including physical inactivity, hypertension, hyperlipidemia, and diabetes mellitus. In addition to lifestyle-related risk factors, health factors including high blood cholesterol levels, high blood pressure, diabetes mellitus, and metabolic syndrome and family history/ genetics also contribute to CVD prevalence.

\subsection{Atherosclerosis Pathophysiology}

Atherosclerosis is the principal CVD of concern; other examples of CVDs include arrhythmia and heart valve problems. Atherosclerosis is a chronic condition of the arterial wall resulting in thickening and hardening of arteries led by a maladaptive inflammatory response, dysregulated lipid metabolism, and plaque build-up. This build-up narrows the arteries, making it harder for blood to flow through, resulting in hypertension. If a blood clot forms, it can stop the blood flow, causing fatal clinical endpoints such as myocardial infarctions (MI) and heart failure, and ischemic stroke in arteries located within the brain ${ }^{[2]}$. Atherosclerosis can cause additional complications such as angio pectoris, limb ischemia, and renal impairment.

The build-up of an atherosclerotic plaque begins with the subendothelial retention of low density lipoprotein (LDL) cholesterol particles and damage in the monolayer of endothelial cells that lines the inner arterial surface, leading to increased permeability to and further retention of LDL particles (Figure 1). Activated endothelial cells express chemotactic chemokines/cytokines (i.e. monocyte chemotactic protein 1, (MCP-1)) and adhesion molecules (i.e. intercellular adhesion molecule-1, (ICAM-1) and vascular cell adhesion molecule-1 (VCAM-1), as well as E-selectin and P-selectin), resulting in enhanced recruitment, attachment, and accumulation of monocytes within the vascular wall. Monocytes differentiate into macrophages upon ingestion of apolipoprotein B (Apo B)containing LDLs.

While subendothelial retention of lipoproteins and immune cells mark the first stage of lesion formation, this initial stage can be either self-resolved by the inflammatory response, and can be considered a type of "wound-healing," or be just one step in plaque progression 
and one effort among many by the body to heal itself back to normal conditions. When plaques progress, macrophages become foam cells (termed due to their foamy morphology upon overloading on lipidic contents), and migrating and resident smooth muscle cells proliferate and synthesize extracellular matrix macromolecules including collagen, elastin, and proteoglycans, contributing to the formation of the fibrous cap that covers the plaque. As the vessel wall continues to remodel and thicken, and the distance from the luminal surface exceeds the oxygen diffusion threshold, tissue ischemia and local hypoxia leads to cell apoptosis of smooth muscle and foam cells. Lipids derived from apoptotic cells accumulate to form the lipid core, located in the central region of atheromas.

Atherosclerotic plaques at the most risk of rupture are defined as vulnerable plaques and can lead to sudden death. The enzymatic activity of matrix metalloproteinases (MMP) derived from apoptotic macrophages can directly cause "softening" of the collagen-stabilized fibrous cap, prompting rupture of the plaque, thrombotic occlusions, and clinical endpoints ${ }^{[3]}$. Advanced atherosclerotic plaques are characterized by a large lipid core consisting of necrotic cells and a thin fibrous cap as well as cholesterol crystals. Before rupture, such lesions are commonly characterized by a fibrous cap of thickness less than $65 \mu \mathrm{m}$, a large lipid-rich, necrotic core that occupies over $50 \%$ of the plaque area, fissures, denudation of the endothelium, a large population of monocytes and macrophages, and superficial platelet aggregation. Moreover, microvessels that are formed upon neovascularization contribute to continuous inflammation, plaque progression, and the recruitment of immune cells. Unlike stenotic lesions, vulnerable plaques are often undetected before the occurrence of clinical events using current diagnostic technologies.

\subsection{Current Diagnostic Modalities and Treatment}

1.3.1. Diagnostic Modalities-Noninvasive imaging technologies have been developed to evaluate the physical and morphological attributes of the vascular wall in an attempt to identify vulnerable plaques. Such technologies include ultrasound, computed tomography (CT), magnetic resonance imaging (MRI), and nuclear imaging (i.e. single-photon emission computed tomography (SPECT) and positron emission tomography (PET)). Since vulnerable plaques are asymptomatic, these clinical imaging modalities are quite limited in their ability to detect instability and have been recently applied in combination with nanoparticles for molecular imaging.

1.3.2. Treatment-Lifestyle changes in diet and exercise are often the best treatment for atherosclerosis. However, several drugs are routinely prescribed including cholesterol lowering drugs, such as statins, fibrates, niacin, bile acid sequestrants, and cholesterol absorption inhibitors, hypertension reducing drugs, such as angiotensin-converting enzyme (ACE) inhibitors, diuretics, beta blockers, and calcium channel blockers, and antithrombosis drugs, such as aspirin and Warfarin. Cholesterol lowering drugs, such as statins, are considered to be first-line therapy for atherosclerosis and statins are well known to inhibit the enzyme HMG-CoA reductase, the rate-controlling enzyme of the mevalonate pathway, or the metabolic pathway that produces cholesterol in the liver. Statins act as competitive inhibitors for the active site on the enzyme and has a higher affinity than HMGCoA. Inhibition of cholesterol synthesis triggers an increase in LDL receptor expression, 
leading to an increased clearance of cholesterol-containing LDL particles. Moreover, several studies have shown that statins may alter LDL particle size, composition, and distribution, and reduce oxidative stress ${ }^{[4-6]}$.

\subsection{Nanomedicine}

Despite their benefits, lipid lowering drugs, like all medications that are administered systemically, have potential for adverse side effects. For instance, statins have been long reported to induce liver and muscle toxicity ${ }^{[7]}$. Liver damage can be measured through increased transaminase levels which occur in approximately $1 \%$ of all patients ${ }^{[8,9]}$. Another major adverse effect of statins is myopathy, or muscle pain or weakness associated with a 10 -fold increase in creatine kinase levels, and rhabdomyolysis, or the breakdown of muscle, and acute renal failure may result if myopathy is not recognized and the drug is continued ${ }^{[10]}$. Moreover, combining statins with fibrates and niacin can also increase the risk of myopathy ${ }^{[7]}$. In addition to liver and muscle toxicity, statins can act on other organs and include adverse effects such as depression, headaches, peripheral neuropathy, erectile dysfunction, reduction in blood clotting capabilities, autoimmune disorders, and various issues affecting the gastrointestinal system (e.g. nausea, dyspepsia, pain, flatulence, diarrhea, and constipation), skin (e.g. alopecia, rash, cheilitis, lichenoid eruption, dermographism, chronic urticaria, and toxic epidemic necrolysis), and eyes (e.g. cataract and ocular hemorrhage $)^{[11,12]}$.

As cholesterol is essential for the structure of the cell membrane and is also important as essential precursors for vitamins and steroid hormones, instead of systemic inhibition, region-specific strategies might be superior for future treatment of atherosclerosis. Moreover, as inflammatory mechanisms are underlying causes of atheroprogression and plaque destabilization, systemic inhibition has limitations as a therapy because many of the molecular targets have important overlapping roles in host defense. As many molecular and cellular events have been identified in the progression of atherosclerosis, such processes provide numerous opportunities as markers for targeting the atherosclerotic plaque ${ }^{[13]}$.

Nanomedicine is the application of nanotechnology to medicine. By attaching antibodies, proteins, peptides or other moieties to its surface, a nanoparticle can be utilized to target receptors or other proteins and structures that are characteristic to diseases including atherosclerosis ${ }^{[14]}$. Although the first nanoparticle platform was first reported in the 60 's, there has been a tremendous rise in investment in nanotechnology for medical applications across the globe just in the last ten years ${ }^{[15]}$. In the United States, the cumulative funding by the National Nanotechnology Initiative (NNI) from 2001 to 2011 was \$14 billion, and the Project on Emerging Nanotechnologies reflected this rise through their reports of over 1300 consumer products on the market encompassing nanotechnology, a 520\% growth from $2006^{[16]}$. Moreover, a search on "nanoparticle" in ClinicalTrials.gov resulted in approximately 185 trials in 2015, up from 80 in 2011. The National Heart, Lung, and Blood Institute (NHLBI) has also recognized the promise of nanotechnology for improving the diagnosis and treatment of cardiovascular diseases, initiating and funding Programs of Excellence in Nanotechnology (PENs) with over a $\$ 100$ million budget ${ }^{[17]}$. 
Nanotechnology is defined by the NNI as the understanding and control of matter at dimensions between approximately 1 and $100 \mathrm{~nm}$, where unique phenomena enable novel applications ${ }^{[17]}$. Today, a myriad of nanosized agents are being developed for applications in atherosclerosis medicine that range from tens of nanometers in size, such as micelles, to hundreds of nanometers, such as liposomes. Nanoparticles can be composed of organic materials such as lipids or peptides, metallic or inorganic materials such as gold and iron oxide, or combinations of these materials. The fabrication of nanoparticles can be precisely controlled, and the physiochemical characteristics including size, shape, surface charge, and stability can be optimized to influence their in vivo behavior such as biodistribution and clearance ${ }^{[18,19]}$. For instance, smaller, spherical nanoparticles $(3-6 \mathrm{~nm})$ are known to distribute widely in a variety of organs by crossing tight endothelial junctions and are often excreted through the renal system. ${ }^{[20-24]}$ Larger particles (>10 nm), on the other hand, are rapidly cleared by the reticuloendothelial system (RES), specifically through sequestration by sinusoids in the spleen and fenestra of the liver. ${ }^{[24,25]}$ The biodistribution and clearance properties of particles within the intermediate range, $6-8 \mathrm{~nm}$, depends upon both size and charge of the particle. ${ }^{[21]}$ In general, while positively-charged nanoparticles have been reported to be readily taken up by macrophages and clearance facilitated by RES due to the interaction with the negatively-charged cell membrane, anionic nanoparticles have been shown to enhance uptake through RES by binding to cationic sites on the macrophage surface. ${ }^{[26,27]}$

Nanoparticle shape can also modulate circulation properties as well as the kinetics of cellular uptake which ultimately affects delivery efficiency. Geng et al. reported that elongated filamentous nanoparticles have extended circulation times compared to spherical nanoparticles, owing to the increased potential to align with blood flow ${ }^{[28]}$. Moreover, according to Gratton et al and Sharma et al, rods and ellipsoids can be internalized into the cell to a greater extent and at a faster degree than spherical particles ${ }^{[29,30]}$.

Nanoparticles have a high surface to volume ratio, allowing particle decoration with a variety of molecules for multifunctionality. While nanoparticles were initially exploited carriers for drug delivery in cancer, and was found to improve pharmacokinetics, biodistribution, and toxicity of a drug in comparison to systemic administration of the drug alone, the insight gained from oncological applications is now being applied toward developing additional superior, targeted, nanomedicine-based strategies for future management of cardiovascular disease, atherosclerosis in particular ${ }^{[31,32]}$.

For the rest of this review article, we summarize and discuss recent advances in targeting strategies in nanomedicine for the treatment and diagnosis of atherosclerosis with a focus on biological or bio-inspired nanoparticles that are formed via self-assembly. While drug delivery, imaging, diagnostic, and theranostic applications and targeting strategies are discussed throughout, we refer the readers to recent reviews that discuss other types of nanoparticles with these applications as well. For a more detailed overview of nanocarriers or polymer-based therapeutics used in the context of atherosclerosis treatment, we refer the reader to recent reviews ${ }^{[33-36]}$. A review of nanoparticles for imaging of atherosclerosis can be found elsewhere ${ }^{[13,37-39]}$. Theranostic nanoparticles with dual therapeutic and diagnostic functionality are reviewed by Eraso et al and Tang et al ${ }^{[40,41]}$. Additional insight regarding 
formulations of nanoparticles and their in vivo behavior can be found in other reviews ${ }^{[42,43]}$. A summary of challenges, clinical barriers, and a future outlook of nanomedicine in atherosclerosis are also discussed herein.

\subsection{Self-Assembling Nanoparticles for Targeting Atherosclerosis}

Self-assembly is the autonomous organization of individual components in patterns of structures without human intervention based on structural information built into the assemblers ${ }^{[44]}$. Self-assembly is essentially a bottom-up process, where atoms or molecules associate into well-defined and functional geometries under specific, controllable thermodynamic conditions ${ }^{[45]}$. Nanoparticles benefit from this bottom-up approach because it allows for precise fabrication of nanoscale features with the potential to scale-up, and a number of interactions may be used to construct such supramolecular nanoparticles including hydrophobic forces, hydrogen bonding, electrostatic, dipole-dipole, and van der Waals. Moreover, through self-assembly, molecules with varying functionality can be incorporated into a single nanoparticle with relative ease. Unlike covalently assembled particles that have permanent structures, self-assembled particles can disassemble at the target, creating different types of release profiles. There are many examples of self-assembly and self-assembling nanoparticles in nature including biological structures such as lipid membranes of vesicles, higher order structured nucleic acids, and multicomponent protein aggregates such as ribosomes. Inspired by nature, the concept of self-assembly has been exploited to develop particles consisting of naturally occurring biomolecules that can be used in the context of atherosclerosis nanomedicine and include liposomes, high density lipoproteins, protein cages, micelles, proticles, and perfluorocarbon nanoparticles, all which are discussed in this review.

2.1.1. Liposomes-Liposomes were first described in the 1960s and are self-assembled vesicles that consist of a phospholipid bilayer, often studied as drug delivery carriers ${ }^{[15]}$. Water-soluble drugs can be encapsulated in the aqueous core of liposomes, while hydrophobic drugs can be embedded within the lipid bilayer. The first clinically approved therapeutic nanomedicine was a liposomal formulation of doxorubicin, a cytotoxic drug for cancer chemotherapy. This formulation, branded Doxil, was approved by the United States Food and Drug Administration in 1995 for the treatment of Kaposi's sarcoma, and became the first of many liposomal therapies to reach commercialization. By encapsulating doxorubicin in liposomes, the pharmacokinetics and biodistribution of the drug is altered compared to the free drug, allowing for a longer circulation half-life and reducing rapid clearance of the drug from the bloodstream, enhanced concentration within the tumors, and decreased toxicity in other tissues. Liposomes with sizes between 50 and $200 \mathrm{~nm}$ and with bilayer membranes between 3 and $5 \mathrm{~nm}$ in thickness are suitable for targeted vascular applications ${ }^{[46]}$. Additional insight regarding liposomal formulation for nanomedicine is provided by Allen et al ${ }^{[42]}$.

By modifying liposomes with targeting ligands, there is potential to further enhance circulation times and reduce its capture by cells of RES, primarily in the liver. Furthermore, when the carrier is targeted to the tissue of interest, the drug release is also localized to that area, resulting in a higher effective drug concentration. The majority of targeting liposomes 
for atherosclerosis applications to date, however, have been developed for imaging purposes as potential diagnostic agents. Ogawa et al. modified liposomes of either 100 or $200 \mathrm{~nm}$ in diameter via an extruder with phosphatidylserine (PS), a component of the phospholipid membrane that is exposed on the surface of apoptotic cells and recognized by macrophages for rapid trigger of phagocytosis ${ }^{[47]}$. They further radiolabeled these liposomes for SPECT imaging by encapsulating ${ }^{111}$ In-nitrlotriacetic acid and used liposomes with phosphatidylcholine (PC) as controls. Liposomes developed for nuclear imaging, such as these, have been rising because nuclear imaging holds the most promise for quantifying plaque components and detecting small quantities of tracer uptake on the molecular and cellular level. Upon intravenous injection into Watanabe heritable hyperlipidemic rabbits, $200 \mathrm{~nm}$ sized liposomes with PS modification were found to be taken up into atherosclerotic regions to the greatest extent using SPECT imaging. As changes in size and nanoparticle formulation can alter uptake and therefore detection capability, further comparisons such as these are needed to move the field forward.

Liposomes with PS modification have also been utilized for MRI applications, a current clinical imaging modality that does not use radiation and is considered to be relatively safe. Maiseyeu and colleagues developed paramagnetic gadolinium liposomes enriched with PS and found macrophages demonstrated a PS concentration dependent uptake in vitro in comparison to control liposomes with no PS ${ }^{[48]}$. In vivo, significant enhancement of the aortic wall was found in Apo E-deficient mice. In addition to targeting, because the PS signal recruits macrophages to clear apoptotic cells, Harel-Adar also found PS-liposomes to simultaneously have reparative effects by promoting angiogenesis and preventing small scars and ventricular dilation/remodeling in rats after MI (Figure 2) ${ }^{[49]}$. This was confirmed via MRI by encapsulation of iron oxide within the liposomes. Whether the secondary effect is reparative or damaging, whole-body analysis upon nanoparticle administration is an aspect of nanomedicine that can be more thoroughly investigated.

To enhance the circulation times of liposomes, the surface can be modified with a hydrophilic polymer, such as polyethylene glycol (PEG). Nanocarriers with a hydrophilic surface are called "stealth" nanoparticles since recognition by mononuclear phagocytes of RES is impaired. Their hydrophilic surface also hinders the blood proteins and opsonins from binding to the particle surface, further avoiding blood clearance, and can enhance circulation times for about 8-10 times longer than standard liposomes ${ }^{[35,50]}$. Recently, Almer and colleagues modified PEGylated liposomes with interleukin-10, or IL-10, an antiinflammatory cytokine whose receptor is more highly expressed on the injured aortic endothelium ${ }^{[51]}$. Using carboxyfluorescein-labeled, IL-10 liposomes, Almer and colleagues found a strong fluorescence intensity at sites of atherosclerotic plaques within Apo Edeficient mice compared to untargeted liposomes. Moreover, no significant immune reaction was found.

Intercellular adhesion molecule-1 (ICAM-1, also known as CD54) is a transmembrane protein that is highly expressed on endothelial cells within fatty streaks that enhances the recruitment of monocytes to plaques, providing a targeting strategy for early stage atherosclerotic plaques. The McPherson group developed inherently echogenic liposomes (ELIP) prepared from PC, phophatidylethanolamine (PE), phosphatidylglycerol (PG), and 
cholesterol, using a dehydration/rehydration method for enhancing ultrasonic images ${ }^{[52,53]}$. Their group further modified these immunoliposomes with antibodies against ICAM-1 and found localization to early atheromas in the Yucatan miniswine model, while liposomes modified with antibodies against fibrinogen, a late marker of atherosclerosis, bound to sites of thrombi using ultrasound ${ }^{[54,55]}$. Whether the resolution required to image stage-specific atherosclerosis is possible within coronary arteries located deeper in the body in humans using ultrasound will require additional studies.

In an additional study, ICAM-1 ELIPs were further modified with antibodies for CD34, a surface marker of stem cells, in an effort to restore the depletion of vascular stem cells that play a critical role for vascular healing in atherosclerosis ${ }^{[56]}$. Moreover, anti-ICAM-1 liposomes have been developed for other imaging regimes including MRI and CT. Paulis et al. incorporated gadolium chelators to the phospholipid membrane while Danila et al. encapsulated iohexol for MRI and CT applications, respectively; both demonstrated targeting potential to endothelial cells in vitro[ ${ }^{[57,58]}$.

In addition to imaging, targeted liposomes have been developed as therapeutic carriers or as nanoparticles with dual diagnostic and therapeutic functions (i.e. theranostic applications). The dual use of nanoparticles for both imaging and targeted delivery of therapeutic agents offers great promise to confirm the drug is reaching the intended target and a molecular effect is occurring. Moreover, the ability to image these particles could be used to estimate local drug concentrations ${ }^{[39]}$. Theranostic liposomes have been modified with antibodies against VCAM-1 for targeting activated endothelial cells and macrophage-foam cells. Homem de Bittencourt et al developed VCAM-1 liposomes containing the antiinflammatory agent, cyclopentenone prostaglandins (LipoCardium) ${ }^{[59]}$. While LDL receptor knock-out mice that did not receive LipoCardium died of myocardium infarction or stroke, mice treated with LipoCardium recovered from these vascular injuries. In vitro, LipoCardium treatment had an anti-inflammatory, anti-proliferative, anti-lipogenic, and cytoprotector effect on macrophages. Liposomes based on the cationic amphiphile SAINTC18 (1-methyl-4-(cis-9-dioleyl)methyl-pyridinium-chloride) have also been modified with antibodies against markers of inflamed endothelial cells, such as VCAM-1 and E-selectin, for siRNA delivery applications ${ }^{[60]}$. These "SAINT-O-Somes" had a 71\% siRNA encapsulation efficiency, and were able to downregulate its target gene in primary endothelial cells. Interestingly, liposomes consisting of cationic lipids alone have been shown to obtain intrinsic targeting potential to vascular injured sites and may be another targeting strategy for drug delivery applications ${ }^{[61]}$.

Targeting liposomes have also encapsulated proangiogenic compounds to improve cardiac function and vascular structure after MI. Scott and colleagues encapsulated vascular endothelial growth factor (VEGF) within P-selectin immunoliposomes and found significant improvements in fractional shortening and systolic function in rats ${ }^{[62]}$. This was accompanied by regenerative response such as an increase in overall vessel number and perfused vessels in the MI region. In another study, Dvir et al conjugated the amino acid sequence of angiotensin II (Gly-Gly-Gly-Gly)-Asp-Val-Tyr-Ile-His-Pro-Phe onto PEGylated liposomes for targeting the angiotensin II type 1 (AT1) receptor which is overexpressed after MI due to hypoxia ${ }^{[63]}$. AT1 liposomes displayed specificity with primary cardiac cells in 
vitro, and accumulated in the left ventricle in mice with infracted hearts. Additional peptides that can be used to target sites of cardiovascular injury include Arg-Gly-Asp (RGD) for targeting the integrin GPIIb-IIa presented on activated platelets ${ }^{[64]}$.

Recent efforts in liposomal work have taken a rational approach to constructing nanoparticles through the use of a materials library to achieve favorable drug delivery outcomes. For example, lipidoids are a class of synthetic vesicles that were synthesized to obtain efficacious delivery properties for siRNA ${ }^{[65]}$. To achieve this, a library of materials was formed in 2008, composed of alkyl-acrylates or alkyl-acrylamides to primary or secondary amines with varying parameters including (i) alkyl chain length from $\mathrm{C} 10$ to $\mathrm{C} 18$, (ii) linkage between the alkyl chain and the amine through the degradable ester or the more stable amide, (iii) primary R group on the amine and (iv) the post-synthetic introduction of a constitutive positive charge to certain lipidoids by quaternization of the amine with the alkylating agent methyl iodide. Additional lipidoids have been developed since this first study to include lipidoids of nondegradable amino alcohols consisting of polar aminecontaining head groups and nonpolar hydrocarbon tails ${ }^{[66]}$. Lipidoid-based nanoparticles have been used to target monocytes and macrophages for efficient siRNA delivery ${ }^{[67,68]}$. Majmudar et al developed lipidoid particles consisting of the C12-200 lipid, dextran, zirconium-89, and siRNA against the C-C-chemokine receptor type 2 (CCR2) for macrophage/monocyte targeting and PET imaging ${ }^{[67]}$. Dextran is a hydrophilic polysaccharide that is known to interact with scavenger receptors on the plasma membrane of macrophages ${ }^{[69]}$. Dextran nanoparticles (DNP) are taken up predominantly in monocytes and macrophages, and PET revealed high uptake of DNP in the aortic root of Apo E -/mice, which corroborated by ex vivo scintillation counting and autoradiography. Moreover, therapeutic silencing of CCR2 was achieved.

2.1.2. High Density Lipoproteins (HDLs)—HDLs are natural nanoparticles 7-13 nm in diameter, composed of multiple biological macromolecules. Along with Apo A-I, the main protein constituent of HDL, cholesterol and phospholipids, particularly PC, make up the bulk of the HDL particle mass. Native HDL, however, is composed of many other components, and their chemical and structural complexity can be further appreciated in other reviews (Figure 3) ${ }^{[70,71]}$. Plasma HDL levels are inversely correlated with the development of atherosclerosis, hence the naming of HDL as "good" cholesterol and associations with atheroprotective properties ${ }^{[72-74]}$. The main mechanism believed to be responsible is reverse cholesterol transport, removing cholesterol from lipid-laden macrophage-foam cells in atherosclerotic lesions. Cholesterol-loaded HDLs are then taken up by hepatocytes of the liver and the cholesterol cargo is excreted in the feces ${ }^{[75,76]}$. HDLs also promote reverse cholesterol transport by transferring cholesteryl esters to LDL species in exchange for triglycerides; LDLs and their cholesterol cargo are then taken up by hepatocytes through the LDL receptor ${ }^{[75]}$. In addition to reverse cholesterol transport, HDL has been reported to have atheroprotective benefits on the endothelium, promote the production of nitric oxide, have antioxidant properties mitigating oxidation of LDLs, and inhibit the inflammatory response ${ }^{[75,77-80]}$. These characteristics make lipoprotein-based nanoparticles mimicking HDL a promising tool for atherosclerosis targeting. 
Artificial, synthetic HDL is often referred to as recombinant HDL (rHDL) and is formed through spontaneous self-assembly of Apo A-I, phospholipids and sodium cholate through a detergent-mediated, dialysis-based synthesis. rHDLs can also be formed by sonicating Apo A-I with phospholipids and then separating formed rHDLs by centrifugation ${ }^{[71,81]}$. rHDLbased nanoparticles can vary in size and function depending on its constituents and have been explored for both diagnostic and therapeutic applications for atherosclerosis. For a thorough review of the synthesis, function, and the clinical applications of native and synthetic HDL nanoparticles, we refer the reader to a comprehensive review by Damiano et $\mathrm{al}^{[70]}$.

rHDL have been frequently modified for utilization as targeting, MRI contrast agents ${ }^{[82]}$. One strategy to achieve targeting to atherosclerotic plaques is through the addition of apolipoproteins that can be found in LDLs. Chen et al developed a rHDL-based nanoparticle consisting of Apo A-I, dipalmitoylphosphatidylcholine (DPPC), rhodaminephosphatidylethanolamine (PE), (diethylenetriaminepentaacetic acid)-bis(stearylamide) (gadolinium salt) (Gd-DTPA-BSA), and sodium cholate ${ }^{[83]}$. This nanoparticle was further modified with the Apo E-derived peptide with the amino acid sequence (LKLR KRLLR) 2 , a tandem dimer derived from the LDL receptor binding domain of Apo E. The mean diameter of these nanoparticles was $11.6 \mathrm{~nm}$ and a significantly higher level of association was found with macrophages in vitro in comparison to the rHDL control. Moreover, in late-stage Apo E -/- mice, the MRI signal was enhanced on the arterial vessel wall and remained high even after 48 hours.

Instead of incorporating constituents of LDL, Sigalov exploited the oxidation changes of Apo A-I to develop gadolinium-based HDL nanoparticles for molecular MRI applications ${ }^{[84]}$. In vivo, two of the three methionines (Met-112 and Met 148) of Apo A-I are oxidized, converting HDL from antiatherogenic to proatherogenic particles. Importantly, the oxidized form of Apo A-I is found in human aortic lesions. Therefore, paramagnetic and fluorescent HDL nanoparticles were developed containing either the oxidized or unmodified Apo A-I protein or peptide sequence. The oxidized nanoparticle was found to be uptaken in macrophages 2-3 times more than the nonoxidated version. In vivo, significant improvements of plaque detection were found in the Apo E -/- mouse compared to the nonmodified counterpart nanoparticles. Confocal fluorescence microscopy confirmed oxidized particles were found in intraplaque macrophages, further demonstrating a naturally occurring oxidation modification of Apo A-I in rHDL can be used as a strategy to target macrophage-rich atherosclerotic plaques for potential diagnostic applications.

In addition to chemical modifications of the Apo A-I protein, peptides mimicking Apo A-I have also been used to develop macrophage-targeting, HDL-based particles for use as MRI contrast agents as well as for therapeutic agents to be taken orally ${ }^{[85,86]}$. Additional peptides, such as those specific for collagen, have also been conjugated to HDL nanoparticles as MRI contrast agents and the ability to evaluate composition changes in atherosclerosis plaque regression assessed ${ }^{[87]}$. The Fisher and Young groups developed the Reversa mouse which possesses 4 homozygous alleles, LDLR-/-Apo $\mathrm{B}^{100 / 100} \mathrm{Mttp}^{\mathrm{fl} / \mathrm{fl}} \mathrm{Max} 1-\mathrm{Cre}^{+/+}$, and is a model of atherosclerosis regression in which microsomal triglyceride transfer protein is conditionally ablated after plaque formation, LDL production falls, and the hyperlipidemic 
plasma profile abates, resulting in a decrease of macrophages and an increase in collagen within plaques leading to more stabled plaques ${ }^{[88]}$. When gadolinium enriched HDL particles consisting of the collagen-specific peptide, GKWH-CTTKFPHHYC, were injected in Reservsa mice, MR images confirmed no signal enhancement at day 0 while an $82 \%$ enhancement was found at day 28 , correlating with an increase in collagen within plaques. This nanoparticle platform may be a strategy that can monitor in vivo plaque compositional changes during plaque regression and can facilitate the search for therapeutic interventions.

Incorporating FDA-approved components into rHDL nanoparticles has been trending and been given much attention in recent years due to the potential for an accelerated regulatory process. For instance, rHDL-mimicking nanoparticles have been modified with biodegradable polymers, such as poly(lactic-co-glycolic acid) (PLGA), for imaging atherosclerosis. Marrache and Dhar developed a polymer-lipid platform consisting of a HDL resembling hydrophobic core of PLGA and a shell consisting of 1,2-distearoyl-snglycero-2phosphoethanolamine (DSPE)-PEG-COOH embedded with cholesterol, Apo A-I mimetic peptides (FAEKFKEAVKDYFAKFWD), and triphenyl phosphonium (TPP) cations containing the steryl-TPP ligand which can be used to direct therapeutic molecules into the mitochondria ${ }^{[89]}$. In vitro, TPP-HDL-Apo A-I nanoparticles bound to cholesterol and was able to differentiate between healthy and apoptotic macrophages. In vivo, TPP-HDL-Apo AI nanoparticles reduced serum total cholesterol and triglyceride levels by mimicking the participation of native HDL in reverse cholesterol transport.

rHDL nanoparticles loaded with FDA-approved drugs such as statins ([S]-rHDL) have also been developed to reduce cholesterol levels ${ }^{[90]}$. When [S]-rHDLs were incubated with murine macrophages, cell survival decreased with the increase in statin dosing, and the reduction in cell viability was correlated with inhibiting the production of inflammatory cytokines and the mevalonate pathway. In vivo biodistribution studies showed nanoparticles to be found mostly in the spleen, liver, and kidneys without cytotoxic effects. Moreover, MRI experiments found [S]-rHDLs infused with gadolium to accumulate within atherosclerotic plaques in Apo E -/- mice, specifically uptaken by intraplaque macrophages. Importantly, Apo E - - mice with advanced atherosclerotic lesions decreased in total plaque area by $31 \%, 34 \%$, and $36 \%$ upon a high dose of [S]-rHDL infusions $(60 \mathrm{mg} / \mathrm{kg}$ simvastatin, $40 \mathrm{mg} / \mathrm{kg}$ Apo A-I, four intravenous infusions per week for one week) compared to the placebo group, rHDL only group, and low-dose [S]-rHDL (15 mg/mL statin, $10 \mathrm{mg} / \mathrm{kg}$ Apo A-I) groups, respectively. The short-term high dose treatment decreased inflammatory protease activity in atherosclerotic plaques and may provide a method to rapidly prevent inflammation in advanced atherosclerotic plaques. Further studies are needed in long-term animal models that contain rupturing plaques and to determine the lasting effects of protection post-regimen. This will provide how these dosage regimens compare to orally taken statins and their clinical relevance.

2.1.3. Protein Cages-Another class of nanoparticles that exists in nature includes supramolecular assemblies of protein subunits that form cage-like architectures. Ferritins, viral capsids, and heat shock proteins are examples of protein cages that have been used in developing imaging platforms for atherosclerosis. Ferritin is a ubiquitous, globular protein complex that consists of 24 protein subunits, plays a role in iron storage and transport, and 
has been reported to accumulate in macrophages in human atherosclerotic plaques ${ }^{[91]}$. Terashima et al loaded iron oxide within fluorescently-labeled ferritins of approximately 12 $\mathrm{nm}$ in diameter for MR imaging of vascular macrophages ${ }^{[92]}$. Upon intravenous injection of ferritin particles in a murine atherosclerosis model of diabetic mice that had ligated left carotid arteries, fluorescence imaging, MRI, and histology confirmed specificity to macrophage-rich regions of atherosclerotic lesions compared to the non-ligated right carotid artery control. As ferritins naturally accumulate within vascular macrophages, the authors suggest that these nanoparticles may be utilized as a noninvasive imaging tool that can intrinsically detect inflammatory lesions without additional targeting moieties. However, as ferritins are present in many cell types, the specificity of accumulation of non-functionalized ferritin particles remains to be determined.

In additional to ferritins, viral capsids are another type of highly ordered, self-assembling proteins cages that have been explored as diagnostic carriers for atherosclerosis. The plant virus tobacco mosaic virus (TMV) has a tubular capsid that measures approximately $300 \times$ $18 \mathrm{~nm}$ and was recently labeled with $\mathrm{Cy} 5, \mathrm{Gd}$ ions chelated with azido-mono amide-1,4,7,10-tetraazacyclododecane- $\mathrm{N}-\mathrm{N}^{\prime}-\mathrm{N}^{\prime \prime}$ - $\mathrm{N}^{\prime \prime \prime}$-tetra acetic acid (Gd(DOTA), and a VCAM-1-targeting peptide for dual-modal imaging of atherosclerotic plaques ${ }^{[93]}$. In Apo E $-/-$ mice, fluorescence imaging indicated selective targeting of VCAM-TMV in diseased aortas in comparison to nontargeting, PEG-TMV control particles (Figure 4). Moreover, VCAM-TMV particles did not accumulate in endothelial cells of healthy mice. For MRI experiments, $10 \mathrm{mg} / \mathrm{kg}$ VCAM-TMV $(0.2 \mathrm{mg} / \mathrm{kg} \mathrm{Gd}, 400$ times lower than clinical MRI contrast agents) was injected into diseased mice and the signal to noise ratio for the vessel wall of the aortas continued to increase over 90 minutes post-injection and peaked at approximately $30 \%$. On the other hand, the signal to noise for free Gd(DOTA) and PBS injected into Apo E -/- mice and VCAM-TMV into healthy C57B1/6 mice remained between 10 and 15 . The significant increase in sensitivity was attributed to the large payload of gadolinium ions delivered per particle in combination with molecular targeting and reduced tumbling rates (effect of shape) increasing the relaxivity per ion. The authors hypothesized that the elongated shape of TMV may contribute synergistically to the molecular targeting strategy as recent reports indicate that rod-shaped nanoparticles provide improved margination properties and therefore enhanced vessel wall targeting compared to spherical particles, increased circulation, and decreased phagocytosis ${ }^{[94]}$. The immunogenicity of particles derived from viruses, however, may be a hurdle that must be fully addressed before translation into the clinic.

Heat shock protein (Hsp) cages have also been demonstrated as a platform for targeted delivery of an imaging agent for atherosclerosis ${ }^{[95]}$. In their study, Uchida and colleagues genetically engineered Hsps from Methanococcus jannaschii by replacing the glycine residue at position 41 on the interior of the surface of the cage with a cysteine for maleimide chemistry with the Cy5.5 imaging agent. Moreover, the LyP-1 amino acid sequence (CGNKRTRGC), known to target lymphatic vessels and macrophages, was introduced at the C-terminus. The Hsp protein cage nanoparticle was self-assembled with 24 subunits and determined to be about $13 \mathrm{~nm}$ in diameter. When macrophages were incubated with LypHsp, enhanced affinity was found in comparison to non targeting Hsp nanoparticles as well as nondifferentiated monocytes. In mice with ligated left common carotid arteries, Lyp-Hsp 
selectively accumulated in macrophage-rich left carotid artery vs. the non-ligated right carotid artery when evaluated in situ and ex vivo. Confocal microscopy further illustrated Lyp-Hsp to target specifically to macrophages within vascular lesions, demonstrating the feasibility of Lyp-1-conjugated Hsp cage nanoparticles as nanoscale platforms for the diagnosis of atherosclerosis.

2.1.4. Micelles-Traditional micelles are defined as closed amphiphilic, lipid monolayers composed of a hydrophobic fatty acid core and a hydrophilic polar surface ${ }^{[96]}$. Lipids in solution self-assemble into micelles when their concentration exceeds the critical micelle concentration (CMC) of the lipid used. The difference between lipids that form micelles and lipids that form liposomes lies in the relative sizes of the hydrophobic tails and hydrophilic headgroups. If the headgroup is much wider than the tail, then the molecule will have a cone-like shape and will form a micelle. In contrast, if the headgroup and tail are similar in width, then the shape will be cylindrical and liposome formation is likely ${ }^{[97,98]}$. In general, micelles are considered to be tens of nanometers in diameter, whereas liposomes can be as large as hundreds of nanometers. A variety of polymeric micelles have been utilized to achieve targeted strategies for atherosclerosis and include micelles consisting of peptide amphiphiles, amphiphilic proteins, amphiphilic carbohydrates, phospholipid-PEG, and MRI contrast agents ${ }^{[99-102]}$.

Peptide amphiphile micelles (PAMs) are a class of synthetic molecules in which a biologically active peptide "headgroup" that is presented at the surface is chemically linked to a hydrophobic "tail." PAMs developed for atherosclerosis are spherical in shape, 10-20 $\mathrm{nm}$ in diameter, and the concentrated multivalent peptide display at the corona has been largely exploited to potentiate binding to a molecular marker that characterizes a specific stage of atherosclerosis. Our earlier studies modified fluorescently labeled PAMs with the fibrin-binding peptide cysteine-arginine-gluatmic acid-lysine-alanine (CREKA) ${ }^{[103,104]}$. These nanoparticles homed to clots found on plaques of late-stage atherosclerotic aortas. In addition to the targeting peptide, the anithrombin peptide, hirulog, was conjugated to the DSPE-PEG hydrophobic tails to form a multifunctional nanoparticle for theranostic applications. While CREKA-PAMs target advanced plaques, recent efforts have been directed towards developing PAMs with markers that have varying expression levels at different stages of atherosclerosis, providing a strategy to monitor the progression of the disease $^{[105,106]}$. It is well known that monocyte accumulation is observed in early lesions. However, in the Apo E -/- mouse, monocyte number and accumulation was found to be continuous and proportional to disease progression ${ }^{[107]}$. Moreover, in humans, rupture-prone plaques in patients have been recently reported to contain a higher number of monocytes ${ }^{[108]}$. Therefore, PAMs that target monocytes were developed through the incorporation of the CCR2-binding motif of MCP-1, and MCP-1 PAMs differentially bound to early and late-stage atherosclerotic aortas (Figure 5). Importantly, PAMs display no toxicity and are cleared through both RES and the renal system, and demonstrate a novel molecular imaging tool and strategy that detects the extent of plaque progression ${ }^{[19,108]}$. Tailoring PAMs for more clinically relevant imaging technologies will determine the true potential of PAMs for atherosclerosis applications. 
DSPE-PEG micelles encapsulating iron oxide nanoparticles (ION) have also been modified with fibrin-targeting peptides ${ }^{[109,110]}$. Starmans et al encapsulated IONs that were approximately $25 \mathrm{~nm}$ in diameter into DSPE-PEG2000 micelles functionalized with a different fibrin-binding peptide, RWQPCPAESWT-Cha-CWDP, through a phase-transfer procedure. The fibrin-targeting ION-micelles increased to $61 \mathrm{~nm}$ in diameter and bound to human blood clots in vitro, confirmed through MRI and magnetic particle spectroscopy, supporting the potential of this platform for MRI applications.

Micelles consisting of targeting sugar and protein moieties are also reported for applications in molecular MRI. The hydroxyl groups of dextran can be conjugated with the carboxyl group of oleic acid, the most abundant hydrophobic fatty acid in human adipose tissue, to synthesize amphiphilic molecules for micelle formation ${ }^{[111]}$. Iron oxide $\left(\mathrm{Fe} \mathrm{O}_{4}\right)$ magnetic nanoclusters were then encapsulated in the core of micelles through the nano-emulsion method and the hydrodynamic sizes ranged from 54.8-94.8 nm. Oleyl dextran-coated magnetic nanoclusters (ODMCs) consisting of low-oleyl-grafted amphiphiles displayed the highest $r 2$ value and were internalized by macrophages through receptor-mediated endocytosis resulting from the interaction of dextran on the surface of the ODMC with scavenger receptors on the macrophages. In a rat artery balloon injury model, $\mathrm{T}_{2}$-weighted MR images confirmed image enhancement of injured tissue after the administration of ODMCs. In another study, van Tilborg and colleagues utilized annexin A5, a protein that binds to PS, to derive macrophage-targeting micelles for fluorescence and MR imaging ${ }^{[112]}$. These bimodal micelles were obtained by mixing Gd-DTPA-DSA, DSPE-PEG2000, DSPEPEG2000-Cy5.5, and DSPE-PEG2000-annexin A5. $\mathrm{T}_{1}$-weighted MR images of atherosclerotic abdominal aortas in Apo E - /- mice clearly showed increased signal intensity after 24 hours post-injection of annexin-micelles. A collagen-binding protein fragment has also been functionalized onto micelles for potential targeting of the fibrous cap and an assessment of vulnerability ${ }^{[113]}$.

Instead of a lipid tail, peptide sequences can be utilized to form both the hydrophobic core and hydrophilic corona of micelles. Recombinant amphiphilic diblock polypeptides based on elastin-mimetic sequences that consist of a N-terminal hydrophilic block [(VPGVG) (VPGEG)(VPGVG)(VPGEG)(VPGVG) $]_{10}$ and a C-terminal hydrophobic block $\left.\left[(\text { IPGVG })_{2} \text { VPGYG(IPGVG }\right)_{2}\right]_{15}$ were modified with fluorescent probes for in vivo imaging ${ }^{[114]}$. In a balloon injury model in rat aortas, elastin-mimetic "protein" (EMP) micelles selectively penetrated the injury site after intravenous administration. Unlike other micelles that have a specific molecular target, EMP micelle uptake is through enhanced vascular permeability-based targeting, characteristic to sites of vessel wall injury.

Therapeutic applications of polymeric micelles have incorporated doxorubicin and oligonucleotides. Recently, a micelle consisting of [poly(N-tert-butylacrylamide)] hydrophobic chains and PEG hydrophilic chains was used to encapsulate doxorubicin to inhibit smooth muscle cell proliferation in vascular endothelial dysfunction ${ }^{[115]}$. Interestingly, an analogue of Evans blue, a dye commonly used in atherosclerosis studies for staining the injured endothelium, was used as the targeting agent. Doxorubicin encapsulated in these polymeric micelles had a sustained release profile over a period of 60 hours and the polymeric micelle was found to absorb directly onto endothelium-injured sites of porcine 
aorta ex vivo. Moreover, Yu and colleagues delivered siRNA to macrophages through mannosylated polymeric micelles ${ }^{[16]}$. These micelles consist of a hydrophobic, $\mathrm{pH}$ responsive block for endosomolysis, a cationic siRNA-condensing block, and a terminal block with reactive sites for "click" bioconjugation with mannose, whose receptor is expressed on M2-like macrophages. These mannosylated nanoparticles improved siRNA delivery into primary macrophages by 4-fold compared to non-targeted carriers, and achieved $87 \%$ knock down. "Smart polymeric micelles" have a surface layer of PEGylation that undergoes matrix metalloproteinase-7-triggered shedding and uncovers a cationic corona for cellular uptake. This delivery platform has also been investigated for siRNA delivery and could provide a delivery platform that has the potential for environmentallytargeted tissue ${ }^{[117]}$. However, in vivo studies in atherosclerosis models will fully determine the applicability of these nanoparticle systems for site-specific drug delivery applications.

In an effort to further stabilize micelles and increase the resistance of thermodynamic disassembly into unimers, York et al report the formation of kinetically assembled, sugarbased nanoparticles comprising of a mucic acid modified with lauroyl groups, PEG, and a terminal functional group, formed through Flash NanoPrecipitation ${ }^{[101]}$. A library of such nanoparticles that included structurally diverse amphiphilic macromolecules varying in hydrophobicity, rigidity, charge, and stereochemistry were investigated to develop various nanoformulations to best mimic features of oxLDL as a strategy to counteract oxLDLscavenger receptor binding ${ }^{[102]}$. In addition to displaying enhanced stability in serum conditions compared to traditional micelles, these micelles exhibit slow circulation clearance with an in vivo half-life of 28 hours. Interestingly, nanoparticles composed of macromolecules with chiral symmetry bound to the receptor in competition with oxLDL. In the Apo E -/- mouse, nanoparticles localized to atherosclerotic plaques while reducing plaque maturity, neointimal hyperplasia, and inflammatory burden. Without a specific homing peptide or antibody, the authors developed a rational materials approach to design targeting particles. The effects of stereochemistry are an aspect that has not been well studied, but could contribute to the efficacy of nanoparticle targeting.

In addition to hydrophobically driven micelle assembly, oppositely charged polypeptides can be utilized to form polyelectrolyte complex micelles (PCM) for atherosclerosis nanomedicine. PCMs are supramolecular nanoparticles that complex through electrostatic interactions. Through the additional of a neutral hydrophilic polymer block such as PEG on either the polyanion or polycation, macroscopic phase separation is blocked while nanometer sized micelles stabilized. These micelles have also been referred to as polyion complex micelles, interpolyelectrolyte complex micelles, or complex coacervate micelles and are especially ideal candidates for encapsulating charged therapeutics such as nucleic acids $^{[118]}$. Although previous targeting strategies using PCMs have focused on conjugating lactose for cancer applications ${ }^{[119]}$, Kuo and colleagues developed VCAM-1 and fibrin (CREKA) targeting PCMs that have potential therapeutic applications in atherosclerosis ${ }^{[120]}$. PCMs were developed by complexing targeting peptide-PEG-lysine30 with nucleic acid inhibitors of either micro RNA-92 or micro RNA-33a ${ }^{[121,122]}$. Micro RNA-92 has been previously demonstrated to be a major contributor to pro-inflammatory endothelial phenotype, while micro RNA-33a has been implicated in promoting atherosclerosis through inhibition of key components in macrophage reverse cholesterol transport ${ }^{130,131}$. VCAM-1 
targeting PCM micelles with micro RNA-92 inhibitors bound to human aortic endothelial cells (HAECs) with specificity in vitro, while fibrin targeting micelles with micro RNA 33 a inhibitors were found to be uptaken by macrophages with the ability to suppress the micro RNA activity without cytotoxic effects. Collectively, their data demonstrated the feasibility for targeted applications of PCMs and the application of micro RNAs for atherosclerosis nanomedicine.

2.1.5. Proticles-Proticles are nucleic acid delivery vehicles that were first reported by the Zimmer group that also utilize electrostatic interactions for nanoparticle assembly ${ }^{[123]}$. Proticles are solid, biodegradable naoparticles that self-assembly through complexation of oppositely charged oligonucleotides and protamine, a cationic 32 amino acid peptide used in depot insulin. The oligonucleotide sequence in proticles is usually noncoding random sequences, simply used for particle assembly. Proticles have been labeled with the globular domain of adipocytokine adiponectin ( $\mathrm{gAd}$ ), which has been previously reported to display anti-inflammatory and anti-atherosclerotic effects by stimulating the production of nitric acid in endothelial cells ${ }^{[124]}$. In the Apo E -/- mice, fluorescently-tagged, gAd-proticles were found to adhere to the arterial wall of atherosclerotic plaques. In contrast, localization of comparable gAd-liposomes was found to accumulate at the outer surface of plaques. The authors suggest these differences may be attributable to charge differences between the two types of particles, which can used to direct binding and internalization behavior.

Almer et al also used proticles for imaging atherosclerotic lesions ${ }^{[125]}$. IL-10-coatedproticles were incubated with sections of aortas dissected from Apo E -/- mice and binding compared with IL-10 conjugated liposomes. Confocal laser scanning microscopy using rhodamine-labeled targeting proticles confirmed IL-10 proticles to bind to regions of atherosclerotic plaques to a greater degree than to the uninjured tissue. However, IL-10liposomes showed a greater amount of staining. In vivo studies of IL-10 proticles will further validate their efficacy and their advantageous over other nanoparticle systems.

2.1.6. Perfluorocarbon Nanoparticles-Perfluorocarbon (PFC) nanoparticles consist of a liquid PFC core encapsulated by a phospholipid monolayer ${ }^{[126]}$. PFCs represent a family of modified hydrocarbon molecules in which the hydrogens are replaced with fluorine atoms. The carbon-fluorine bond is very stable and biologically inert, and PFCs with molecular weights between 460 and 520 are biocompatible, and shows no toxicity, carcinogenicity, mutagenicity, or teratogenic effects. PFCs have tissue half-life residencies ranging from 4 to 65 days. Instead of being metabolized, they are reintroduced into the blood circulation from clearance organs, such as the liver, by lipid carriers and are exhaled via the lungs ${ }^{[127]}$. Typical particles for drug delivery applications are approximately $250 \mathrm{~nm}$ in diameter. In contrast to liposomal drug delivery, which generally requires endocytosis, the mechanism of drug transport involves lipid exchange or lipid mixing between the emulsion vesicle and the targeted cell membrane, or "contact facilitated drug delivery ${ }^{[39]}$."

While many studies utilized PFC nanoparticles for cancer applications ${ }^{[128,129]}$, VCAM-1 or fibrin-targeting PFC nanoparticles have been developed for applications in atherosclerosis ${ }^{[130]}$. Pan and colleagues generated VCAM-1 targeting PFC nanoparticles ${ }^{[131]}$. Briefly, a lipid/surfactant comixture of $99 \mathrm{~mol} \%$ egg lecithin and $1 \mathrm{~mol} \%$ 
DSPE dissolved in methanol/chloroform was used to produce a lipid film. Then PFC, antiVCAM-1 targeting peptides, and water was added, blended, and emulsified to develop PFC nanoparticles (Figure 6). The hydrodynamic diameter of the PFC nanoparticles was found to be approximately $230 \mathrm{~nm}$ in diameter, were found to be stable enough to remain functional for biomarker targeting, and targeted atherosclerotic aortas in Apo E - $/-$ mice by 4.1 fold in comparison to nontargeted nanoparticles using magnetic resonance spectroscopy. Moreover, Winter and colleagues showed paramagnetic PFC nanoparticles that target thrombi to be useful for detection of pre-rupture plaques using MRI ${ }^{[132]}$. Gd-DTPA was included in the surfactant mixture to be incorporated in the lipid membrane and anti-fibrin antibodies coupled to the nanoparticle to develop molecular MRI agents. These nanoparticles had enhanced relaxivities when compared to Gd-DTPA-bisoleate nanoparticles due to faster water exchange with surface gadolinium, and had increased binding to thrombus surfaces over fibrin-binding Gd-DTPA-bisoleate nanoparticles in vitro.

\subsection{Conclusion: Current Problems and Future Perspectives}

More than 50 years has passed since the late Nobel Laureate Richard Feynman delivered a keynote speech at the American Physical Society; his famous words "There's plenty of room at the bottom" referred to how science at the nanoscale can be harnessed for large-scale benefits. Since then, the field of nanomedicine has been developed in an effort to more efficiently and more safely treat and diagnose various diseases such as cancer and cardiovascular disease. Self-assembling nanoparticles represent a potent alternative to smallmolecule drugs owing to their improved bioavailability, ability to easily incorporate multiple functionality including targeting ligands, biodegradability, and ability to scale-up without compromising molecular control. However, nanoparticles also have limitations in some cases, including immunostimulatory and immunosuppressive properties ${ }^{[37]}$. Whether it is possible to specifically target chronic inflammatory responses in atherosclerosis without impairing host defense in acute inflammation is yet to be answered.

Many of the exciting preclinical findings with self-assembling nanoparticles have not progressed further into animal models or into clinical trials. One of the main reasons for this is the accelerated development of atherosclerosis in animal models such as the Apo E-/- or Ldlr-/- murine model, the two most commonly used models of atherosclerosis in the laboratory, thereby creating atherosclerotic lesions with properties different from those found in humans ${ }^{[13,133]}$. Another issue is the variability between different animal models, including diets and methods for developing plaques, illustrating the need for the standardization of animal models of atherosclerosis ${ }^{[134]}$. While porcine vasculature and its diseases have the closest resemblance to humans, the cost and space required to conduct large animal studies often limit the number of animals purchased to obtain the power needed to conduct a thorough study. In addition, due to the complex and chronic nature of atherosclerosis, in vitro models of atherosclerosis are not easily developed.

Another challenge that must be addressed is the ability to diagnose a vulnerable plaque phenotype well before fatal clinical endpoints like myocardial infarction and stroke occur. Since vulnerable plaques are asymptomatic and atherosclerosis a chronic disease, at what point nanoparticles will be used during patient care and the cost analysis of nanoparticle 
injections for prolonged periods of time is yet to be determined. Perhaps, additional efforts in atherosclerosis biology and new insights regarding imaging will allow for improved stagespecific targeting. As such, the development of targeted nanoparticles for atherosclerosis will continue to evolve with technological advances and as our understanding of the molecular pathogenesis of the disease is better understood. Moreover, pharmacokinetic, biodistribution, clearance, and toxicity studies will further validate their applicability in patients, and identification of nanoparticle formulations through materials libraries for achieving optimal retention periods and clearance rates for specific use (i.e. therapeutic vs. diagnostic vs. theranostic) will be critical for this effort. Insight into tuning the physiochemical and structural features (i.e. size, charge, shape) such as PEGylation (i.e. surface density and molecular weight) offers one strategy to tailor the intracellular and systemic pharmacokinetic properties ${ }^{[135]}$. In addition, blood rheology and hemodynamics should also be considered for favorable marginations of nanoparticles to the vascular wall ${ }^{[136]}$. Perhaps comparisons between the nanoparticle types would also accelerate our understanding and nanoparticle adoption into clinical use. While additional questions remain to be answered, self-assembling nanoparticles hold promise for targeted strategies in the diagnosis and management of atherosclerosis. The formulation of multifunctional nanoassemblies is made possible by the range of available composition, and the field continues to move towards personalized medicine regimes with the rising number of studies for theranostic applications and stage-specific targeting.

\section{Acknowledgments}

The authors would like to acknowledge the financial support from the University of Chicago and the National Heart, Lung, and Blood Institute (NHLBI) K99HL124279 granted to E.J.C. Our work in this field was initiated under the auspices of the NHLBI Program for Excellence in Nanotechnology.

\section{References}

1. Mozaffarian D, Benjamin EJ, Go AS, Arnett DK, Blaha MJ, Cushman M, de Ferranti S, Després JP, Fullerton HJ, Howard VJ, Huffman MD, Judd SE, Kissela BM, Lackland DT, Lichtman JH, Lisabeth LD, Liu S, Mackey RH, Matchar DB, McGuire DK, Mohler ER, Moy CS, Muntner P, Mussolino ME, Nasir K, Neumar RW, Nichol G, Palaniappan L, Pandey DK, Reeves MJ, Rodriguez CJ, Sorlie PD, Stein J, Towfighi A, Turan TN, Virani SS, Willey JZ, Woo D, Yeh RW, Turner MB. Circulation. 2014; 129:e28. [PubMed: 24352519]

2. Association AH. What is Cardiovascular Disease?. 2014

3. Wilson HM. Journal of Cellular and Molecular Medicine. 2010; 14:2055. [PubMed: 20629993]

4. Rosenson RS. Atherosclerosis. 2004; 173:1. [PubMed: 15177118]

5. Otvos JD, Shalaurova I, Freedman DS, Rosenson RS. Atherosclerosis. 2002; 160:41. [PubMed: 11755921]

6. Forster LF, Stewart G, Bedford D, Stewart JP, Rogers E, Shepherd J, Packard CJ, Caslake MJ. Atherosclerosis. 2002; 164:129. [PubMed: 12119202]

7. Maron DJ, Fazio S, Linton MF. Circulation. 2000; 101:207. [PubMed: 10637210]

8. Lancet. 1994; 344:1383. [PubMed: 7968073]

9. Bradford RH, Shear CL, Chremos AN, Dujovne C, Downton M, Franklin FA, Gould AL, Hesney M, Higgins J, Hurley DP, et al. Archives of Internal Medicine. 1991; 151:43. [PubMed: 1985608]

10. Pierce LR, Wysowski DK, Gross TP. Jama. 1990; 264:71. [PubMed: 2355431]

11. Beltowski J, Wojcicka G, Jamroz-Wisniewska A. Current Drug Safety. 2009; 4:209. [PubMed: 19534648] 
12. Kiortsis DN, Filippatos TD, Mikhailidis DP, Elisaf MS, Liberopoulos EN. Atherosclerosis. 2007; 195:7. [PubMed: 17094994]

13. Lobatto ME, Fuster V, Fayad ZA, Mulder WJM. Nat Rev Drug Discov. 2011; 10:835. [PubMed: 22015921]

14. Shi J, Xiao Z, Kamaly N, Farokhzad OC. Accounts of Chemical Research. 2011; 44:1123. [PubMed: 21692448]

15. Sessa G, Weissmann G. Journal of Lipid Research. 1968; 9:310. [PubMed: 5646182]

16. Executive Office of the President's Council of Advisors on Science and Technology. 2010; 3

17. Buxton DB. Circulation Research. 2011; 109:250. [PubMed: 21778434]

18. Mitragotri S, Lahann J. Nat Mater. 2009; 8:15. [PubMed: 19096389]

19. Chung EJ, Mlinar LB, Sugimoto MJ, Nord K, Roman BB, Tirrell M. Nanomedicine: Nanotechnology, Biology and Medicine. 2015; 11:479.

20. Choi HS, Liu W, Misra P, Tanaka E, Zimmer JP, Ipe BI, Bawendi MG, Frangioni JV. Nature Biotechnology. 2007; 25:1165.

21. Longmire M, Choyke PL, Kobayashi H. Nanomedicine. 2008; 3:703. [PubMed: 18817471]

22. Champion JA, Walker A, Mitragotri S. Pharmaceutical Research. 2008; 25:1815. [PubMed: 18373181]

23. Vonarbourg A, Passirani C, Saulnier P, Benoit J-P. Biomaterials. 2006; 27:4356. [PubMed: 16650890]

24. Duan X, Li Y. Small. 2013; 9:1521. [PubMed: 23019091]

25. Burns AA, Vider J, Ow H, Herz E, Penate-Medina O, Baumgart M, Larson SM, Wiesner U, Bradbury M. Nano Letters. 2008; 9:442. [PubMed: 19099455]

26. Rigotti A, Acton SL, Krieger M. Journal of Biological Chemistry. 1995; 270:16221. [PubMed: 7541795]

27. Roser M, Fischer D, Kissel T. European Journal of Pharmaceutics and Biopharmaceutics. 1998; 46:255. [PubMed: 9885296]

28. Geng Y, Dalhaimer P, Cai S, Tsai R, Tewari M, Minko T, Discher DE. Nature Nanotechnology. 2007; 2:249.

29. Gratton SE, Ropp PA, Pohlhaus PD, Luft JC, Madden VJ, Napier ME, DeSimone JM. PNAS. 2008; 105:11613. [PubMed: 18697944]

30. Sharma G, Valenta DT, Altman Y, Harvey S, Xie H, Mitragotri S, Smith JW. Journal of Controlled Release. 2010; 147:408. [PubMed: 20691741]

31. Uziely B, Jeffers S, Isacson R, Kutsch K, Wei-Tsao D, Yehoshua Z, Libson E, Muggia FM, Gabizon A. Journal of Clinical Oncology. 1995; 13:1777. [PubMed: 7602367]

32. Gabizon A, Isacson R, Libson E, Kaufman B, Uziely B, Catane R, Ben-Dor CG, Rabello E, Cass Y, Peretz T, Sulkes A, Chisin R, Barenholz Y. Acta Oncologica. 1994; 33:779. [PubMed: 7993646]

33. Howard MD, Hood ED, Zern B, Shuvaev VV, Grosser T, Muzykantov VR. Annual Review of Pharmacology and Toxicology. 2014; 54:205.

34. Chacko AM, Hood ED, Zern BJ, Muzykantov VR. Current Opinion in Colloid \& Interface Science. 2011; 16:215. [PubMed: 21709761]

35. Schiener M, Hossann M, Viola JR, Ortega-Gomez A, Weber C, Lauber K, Lindner LH, Soehnlein O. Trends in Molecular Medicine. 20:271. [PubMed: 24594264]

36. Lewis DR, Kamisoglu K, York AW, Moghe PV. Nanomedicine and Nanobiotechnology. 2011; 3:400. [PubMed: 21523920]

37. Psarros C, Lee R, Margaritis M, Antoniades C. Maturitas. 73:52. [PubMed: 22261366]

38. Kanwar RK, Chaudhary R, Tsuzuki T, Kanwar JR. Nanomedicine. 2012; 7:899. [PubMed: 22715913]

39. Wickline SA, Neubauer AM, Winter PM, Caruthers SD, Lanza GM. Journal of Magnetic Resonance Imaging. 2007; 25:667. [PubMed: 17347992]

40. Eraso LH, Reilly MP, Sehgal C, Mohler ER. Vascular Medicine. 2011; 16:145. [PubMed: 21310769] 
41. Tang J, Lobatto ME, Read JC, Mieszawska AJ, Fayad ZA, Mulder WJ. Current cardiovascular imaging reports. 2012; 5:19. [PubMed: 22308199]

42. Allen TM, Cullis PR. Advanced Drug Delivery Reviews. 2013; 65:36. [PubMed: 23036225]

43. Mishra B, Patel BB, Tiwari S. Nanomedicine: Nanotechnology, Biology and Medicine. 2010; 6:9.

44. Whitesides GM, Grzybowski B. Science. 2002; 295:2418. [PubMed: 11923529]

45. Rajagopalan T, Venumadhav K, Arkasubhra G, Nripen C, Keshab G, Shubhra G. Reports on Progress in Physics. 2013; 76:066501. [PubMed: 23722189]

46. Moghimi SM, Szebeni J. Progress in Lipid Research. 2003; 42:463. [PubMed: 14559067]

47. Ogawa M, Umeda IO, Kosugi M, Kawai A, Hamaya Y, Takashima M, Yin H, Kudoh T, Seno M, Magata Y. Journal of Nuclear Medicine. 2014; 55:115. [PubMed: 24337605]

48. Maiseyeu A, Mihai G, Kampfrath T, Simonetti OP, Sen CK, Roy S, Rajagopalan S, Parthasarathy S. Journal of Lipid Research. 2009; 50:2157. [PubMed: 19017616]

49. Harel-Adar T, Mordechai TB, Amsalem Y, Feinberg MS, Leor J, Cohen S. PNAS. 2011; 108:1827. [PubMed: 21245355]

50. Gref R, Lück M, Quellec P, Marchand M, Dellacherie E, Harnisch S, Blunk T, Müller RH. Colloids and Surfaces B: Biointerfaces. 2000; 18:301. [PubMed: 10915952]

51. Almer G, Frascione D, Pali-Schöll I, Vonach C, Lukschal A, Stremnitzer C, Diesner SC, JensenJarolim E, Prassl R, Mangge H. Molecular Pharmaceutics. 2012; 10:175. [PubMed: 23176185]

52. AlkanOnyuksel H, Demos SM, Lanza GM, Vonesh MJ, Klegerman ME, Kane BJ, Kuszak J, McPherson DD. Journal of Pharmaceutail. Sciences. 1996; 85:486.

53. Buchanan KD, Huang S, Kim H, Macdonald RC, McPherson DD. Journal of Pharmaceutail Sciences. 2008; 97:2242.

54. Demos SM, Alkan-Onyuksel H, Kane BJ, Ramani K, Nagaraj A, Greene R, Klegerman M, McPherson DD. Journal of the American College of Cardiology. 1999; 33:867. [PubMed: 10080492]

55. Demos SM, Dagar S, Klegerman M, Nagaraj A, McPherson DD, Onyuksel H. Journal of Drug Targeting. 1998; 5:507. [PubMed: 9783681]

56. Herbst SM, Klegerman ME, Kim H, Qu J, Shelat H, Wassler M, Moody MR, Yang C-M, Ge X, Zou Y, Kopechek JA, Clubb FJ, Kraemer DC, Huang S, Holland CK, McPherson DD, Geng Y-J. Molecular Pharmaceutics. 2010; 7:3. [PubMed: 19719324]

57. Paulis L, Jacobs I, van den Akker N, Geelen T, Molin D, Starmans L, Nicolay K, Strijkers G. Journal of Nanobiotechnology. 2012; 10:25. [PubMed: 22716048]

58. Danila D, Partha R, Elrod DB, Lackey M, Casscells SW, Conyers JL. Texas Heart Institute Journal. 2009; 36:393. [PubMed: 19876414]

59. Homem de Bittencourt PI Jr, Lagranha DJ, Maslinkiewicz A, Senna SM, Tavares AMV, Baldissera LP, Janner DR, Peralta JS, Bock PM, Gutierrez LLP, Scola G, Heck TG, Krause MS, Cruz LA, Abdalla DSP, Lagranha CJ, Lima T, Curi R. Atherosclerosis. 2007; 193:245. [PubMed: 16996518]

60. Kowalski PS, Lintermans LL, Morselt HWM, Leus NGJ, Ruiters MHJ, Molema G, Kamps JAAM. Molecular Pharmaceutics. 2013; 10:3033. [PubMed: 23819446]

61. Joner M, Morimoto K, Kasukawa H, Steigerwald K, Merl S, Nakazawa G, John MC, Finn AV, Acampado E, Kolodgie FD, Gold HK, Virmani R. Arteriosclerosis, Thrombosis, and Vascular Biology. 2008; 28:1960.

62. Scott RC, Rosano JM, Ivanov Z, Wang B, Chong PL-G, Issekutz AC, Crabbe DL, Kiani MF. The FASEB Journal. 2009; 23:3361. [PubMed: 19535683]

63. Dvir T, Bauer M, Schroeder A, Tsui JH, Anderson DG, Langer R, Liao R, Kohane DS. Nano Letters. 2011; 11:4411. [PubMed: 21899318]

64. Lestini BJ, Sagnella SM, Xu Z, Shive MS, Richter NJ, Jayaseharan J, Case AJ, Kottke-Marchant K, Anderson JM, Marchant RE. Journal of Controlled Release. 2002; 78:235. [PubMed: 11772464]

65. Akinc A, Zumbuehl A, Goldberg M, Leshchiner ES, Busini V, Hossain N, Bacallado SA, Nguyen DN, Fuller J, Alvarez R, Borodovsky A, Borland T, Constien R, de Fougerolles A, Dorkin JR, Narayanannair Jayaprakash K, Jayaraman M, John M, Koteliansky V, Manoharan M, Nechev L, 
Qin J, Racie T, Raitcheva D, Rajeev KG, Sah DWY, Soutschek J, Toudjarska I, Vornlocher H-P, Zimmermann TS, Langer R, Anderson DG. Nat Biotech. 2008; 26:561.

66. Love KT, Mahon KP, Levins CG, Whitehead KA, Querbes W, Dorkin JR, Qin J, Cantley W, Qin LL, Racie T, Frank-Kamenetsky M, Yip KN, Alvarez R, Sah DWY, de Fougerolles A, Fitzgerald K, Koteliansky V, Akinc A, Langer R, Anderson DG. PNAS. 2010; 107:1864. [PubMed: 20080679]

67. Majmudar MD, Yoo J, Keliher EJ, Truelove JJ, Iwamoto Y, Sena B, Dutta P, Borodovsky A, Fitzgerald K, Di Carli MF, Libby P, Anderson DG, Swirski FK, Weissleder R, Nahrendorf M. Circulation Research. 2013; 112:755. [PubMed: 23300273]

68. Courties G, Heidt T, Sebas M, Iwamoto Y, Jeon D, Truelove J, Tricot B, Wojtkiewicz G, Dutta P, Sager HB, Borodovsky A, Novobrantseva T, Klebanov B, Fitzgerald K, Anderson DG, Libby P, Swirski FK, Weissleder R, Nahrendorf M. Journal of the American College of Cardiology. 2014; 63:1556. [PubMed: 24361318]

69. Tsubamoto Y, Yamada N, Watanabe Y, Inaba T, Shiomi M, Shimano H, Gotoda T, Harada K, Shimada M, Ohsuga J, et al. Atherosclerosis. 1994; 106:43. [PubMed: 8018106]

70. Damiano MG, Mutharasan RK, Tripathy S, McMahon KM, Thaxton CS. Advanced Drug Delivery Reviews. 2013; 65:649. [PubMed: 22921597]

71. Jonas, A.; Phillips, MC. Biochemistry of Lipids, Lipoproteins and Membranes (Fifth Edition). Vance, Dennis E.; Vance, Jean E., editors. Elsevier; 2008. p. 485-506.

72. Wilson PW, Abbott RD, Castelli WP. Arteriosclerosis. 1988; 8:737. [PubMed: 3196218]

73. Maxfield FR, Tabas I. Nature. 2005; 438:612. [PubMed: 16319881]

74. Chamberlain AM, Folsom AR, Heckbert SR, Rosamond WD, Cushman M. Blood. 2008; 112:2675. [PubMed: 18614761]

75. Rader DJ, Alexander ET, Weibel GL, Billheimer J, Rothblat GH. Journal of Lipid Research. 2009; 50(Suppl):S189. [PubMed: 19064999]

76. Fielding CJ, Fielding PE. Journal of Lipid Research. 1995; 36:211. [PubMed: 7751809]

77. Seetharam D, Mineo C, Gormley AK, Gibson LL, Vongpatanasin W, Chambliss KL, Hahner LD, Cummings ML, Kitchens RL, Marcel YL, Rader DJ, Shaul PW. Circulation Research. 2006; 98:63. [PubMed: 16339487]

78. Yuhanna IS, Zhu Y, Cox BE, Hahner LD, Osborne-Lawrence S, Lu P, Marcel YL, Anderson RG, Mendelsohn ME, Hobbs HH, Shaul PW. Nature medicine. 2001; 7:853-857.

79. Suc I, Escargueil-Blanc I, Troly M, Salvayre R, Nègre-Salvayre A. Arteriosclerosis, Thrombosis, and Vascular Biology. 1997; 17:2158.

80. Kontush A, Chapman MJ. Current Opinion in Lipidology. 2010; 21:312. [PubMed: 20581677]

81. Jonas A. Methods in Enzymology. 1986; 128:553. [PubMed: 3724523]

82. Jung C, Kaul MG, Bruns OT, Dučić T, Freund B, Heine M, Reimer R, Meents A, Salmen SC, Weller H, Nielsen P, Adam G, Heeren J, Ittrich H. Circulation: Cardiovascular Imaging. 2014; 7:303. [PubMed: 24357264]

83. Chen W, Vucic E, Leupold E, Mulder WJM, Cormode DP, Briley-Saebo KC, Barazza A, Fisher EA, Dathe M, Fayad ZA. Contrast Media \& Molecular Imaging. 2008; 3:233. [PubMed: 19072768]

84. Sigalov AB. Contrast Media \& Molecular Imaging. 2014; 9:372. [PubMed: 24729189]

85. Cormode DP, Briley-Saebo KC, Mulder WJM, Aguinaldo JGS, Barazza A, Ma Y, Fisher EA, Fayad ZA. Small. 2008; 4:1437. [PubMed: 18712752]

86. Zhao Y, Black AS, Bonnet DJ, Maryanoff BE, Curtiss LK, Leman LJ, Ghadiri MR. Journal of Lipid Research. 2014; 55:2053. [PubMed: 24975585]

87. Chen W, Cormode DP, Vengrenyuk Y, Herranz B, Feig JE, Klink A, Mulder WJM, Fisher EA, Fayad ZA. JACC Cardiovascular Imaging. 2013; 6:373. [PubMed: 23433925]

88. Lieu HD, Withycombe SK, Walker Q, Rong JX, Walzem RL, Wong JS, Hamilton RL, Fisher EA, Young SG. Circulation. 2003; 107:1315. [PubMed: 12628954]

89. Marrache S, Dhar S. PNAS. 2013; 110:9445. [PubMed: 23671083]

90. Duivenvoorden R, Tang J, Cormode DP, Mieszawska AJ, Izquierdo-Garcia D, Ozcan C, Otten MJ, Zaidi N, Lobatto ME, van Rijs SM, Priem B, Kuan EL, Martel C, Hewing B, Sager H, Nahrendorf 
M, Randolph GJ, Stroes ESG, Fuster V, Fisher EA, Fayad ZA, Mulder WJM. Nature Communications. 2014:5.

91. Yuan XM. Free Radical Research. 1999; 30:221. [PubMed: 10711792]

92. Terashima M, Uchida M, Kosuge H, Tsao PS, Young MJ, Conolly SM, Douglas T, McConnell MV. Biomaterials. 2011; 32:1430. [PubMed: 21074263]

93. Bruckman MA, Jiang K, Simpson EJ, Randolph LN, Luyt LG, Yu X, Steinmetz NF. Nano Letters. 2014; 14:1551. [PubMed: 24499194]

94. Wen A, Rambhia P, French R, Steinmetz N. J Biol Phys. 2013; 39:301. [PubMed: 23860875]

95. Uchida M, Kosuge H, Terashima M, Willits DA, Liepold LO, Young MJ, McConnell MV, Douglas T. ACS Nano. 2011; 5:2493. [PubMed: 21391720]

96. Cormode DP, Naha PC, Fayad ZA. Contrast Media \& Molecular Imaging. 2014; 9:37. [PubMed: 24470293]

97. Trent A, Marullo R, Lin B, Black M, Tirrell M. Soft Matter. 2011; 7:9572.

98. Israelachvili JN, Mitchell DJ, Ninham BW. Biochimica et Biophysica Acta (BBA) Biomembranes. 1977; 470:185. [PubMed: 911827]

99. Sawant RR, Jhaveri AM, Torchilin VP. Advanced Drug Delivery Reviews. 2012; 64:1436. [PubMed: 22917778]

100. Maiseyeu A, Bagalkot V. Nanoscale Research Letters. 2014; 9:176. [PubMed: 24725273]

101. York AW, Zablocki KR, Lewis DR, Gu L, Uhrich KE, Prud'homme RK, Moghe PV. Advanced Materials. 2012; 24:733. [PubMed: 22223224]

102. Lewis DR, Petersen LK, York AW, Zablocki KR, Joseph LB, Kholodovych V, Prud'homme RK, Uhrich KE, Moghe PV. PNAS. 2015; 112:2693. [PubMed: 25691739]

103. Peters D, Kastantin M, Kotamraju VR, Karmali PP, Gujraty K, Tirrell M, Ruoslahti E. PNAS. 2009; 106:9815. [PubMed: 19487682]

104. Chung EJ, Cheng Y, Morshed R, Nord K, Han Y, Wegscheid ML, Auffinger B, Wainwright DA, Lesniak MS, Tirrell MV. Biomaterials. 2014; 35:1249. [PubMed: 24211079]

105. Mlinar LB, Chung EJ, Wonder EA, Tirrell M. Biomaterials. 2014; 35:8678. [PubMed: 25043572]

106. Chung EJ, Mlinar LB, Nord K, Sugimoto MJ, Wonder E, Alenghat FJ, Fang Y, Tirrell M. Advanced Healthcare Materials. 2015; 4:367. [PubMed: 25156590]

107. Swirski FK, Pittet MJ, Kircher MF, Aikawa E, Jaffer FA, Libby P, Weissleder R. PNAS. 2006; 103:10340. [PubMed: 16801531]

108. Kashiwagi M, Imanishi T, Tsujioka H, Ikejima H, Kuroi A, Ozaki Y, Ishibashi K, Komukai K, Tanimoto T, Ino Y, Kitabata H, Hirata K, Akasaka T. Atherosclerosis. 2010; 212:171. [PubMed: 20684824]

109. Starmans LWE, Burdinski D, Haex NPM, Moonen RPM, Strijkers GJ, Nicolay K, Grüll H. PLoS ONE. 2013; 8:e57335. [PubMed: 23437371]

110. Starmans LWE, Moonen RPM, Aussems-Custers E, Daemen MJAP, Strijkers GJ, Nicolay K, Grüll H. PLoS ONE. 2015; 10:e0119257. [PubMed: 25746677]

111. Kim M-H, Kim B, Lim E-K, Choi Y, Choi J, Kim E, Jang E, Park HS, Suh J-S, Huh Y-M, Haam S. Macromolecular Bioscience. 2014; 14:943. [PubMed: 24740644]

112. van Tilborg GAF, Vucic E, Strijkers GJ, Cormode DP, Mani V, Skajaa T, Reutelingsperger CPM, Fayad ZA, Mulder WJM, Nicolay K. Bioconjugate Chemistry. 2010; 21:1794. [PubMed: 20804153]

113. van Bochove GS, Sanders HMHF, de Smet M, Keizer HM, Mulder WJM, Krams R, Strijkers GJ, Nicolay K. European Journal of Inorganic Chemistry. 2012; 2012:2115.

114. Kim W, Brady C, Chaikof EL. Acta Biomaterialia. 2012; 8:2476. [PubMed: 22504077]

115. Ikuta K, Mori T, Yamamoto T, Niidome T, Shimokawa H, Katayama Y. Bioorganic \& Medicinal Chemistry. 2008; 16:2811. [PubMed: 18226910]

116. Yu SS, Lau CM, Barham WJ, Onishko HM, Nelson CE, Li H, Smith CA, Yull FE, Duvall CL, Giorgio TD. Molecular Pharmaceutics. 2013; 10:975. [PubMed: 23331322]

117. Li H, Yu SS, Miteva M, Nelson CE, Werfel T, Giorgio TD, Duvall CL. Advanced Functional Materials. 2013; 23:3040. [PubMed: 25214828] 
118. Akagi D, Oba M, Koyama H, Nishiyama N, Fukushima S, Miyata T, Nagawa H, Kataoka K. Gene Therapy. 2007; 14:1029. [PubMed: 17460721]

119. Oishi M, Nagasaki Y, Nishiyama N, Itaka K, Takagi M, Shimamoto A, Furuichi Y, Kataoka K. ChemMedChem. 2007; 2:1290. [PubMed: 17546711]

120. Kuo C-H, Leon L, Chung EJ, Huang R-T, Sontag TJ, Reardon CA, Getz GS, Tirrell M, Fang Y. Journal of Materials Chemistry B. 2014; 2:8142.

121. Fang Y, Davies PF. Arteriosclerosis, Thrombosis, and Vascular Biology. 2012; 32:979.

122. Najafi-Shoushtari SH, Kristo F, Li Y, Shioda T, Cohen DE, Gerszten RE, Näär AM. Science. 2010; 328:1566. [PubMed: 20466882]

123. Junghans M, Kreuter J, Zimmer A. Nucleic Acids Research. 2000; 28:e45. [PubMed: 10773093]

124. Almer G, Wernig K, Saba-Lepek M, Haj-Yahya S, Rattenberger J, Wagner J, Gradauer K, Frascione D, Pabst G, Leitinger G, Mangge H, Zimmer A, Prassl R. International Journal of Nanomedicine. 2011; 6:1279. [PubMed: 21753879]

125. Almer G, Summers KL, Scheicher B, Kellner J, Stelzer I, Leitinger G, Gries A, Prassl R, Zimmer A, Mangge H. International Journal of Nanomedicine. 2014; 9:4211. [PubMed: 25214785]

126. Winter, P.; Lanza, G.; Wickline, S. Ch. 94. In: Bhushan, Bharat, editor. Encyclopedia of Nanotechnology. Springer Netherlands; 2012. p. 2040-2051.

127. Pan D, Caruthers SD, Chen J, Winter PM, SenPan A, Schmieder AH, Wickline SA, Lanza GM. Future Medicinal Chemistry. 2010; 2:471. [PubMed: 20485473]

128. Pan D, Schmieder AH, Wang K, Yang X, Senpan A, Cui G, Killgore K, Kim B, Allen JS, Zhang H, Caruthers SD, Shen B, Wickline SA, Lanza GM. Theranostics. 2014; 4:565. [PubMed: 24723979]

129. Tran TD, Caruthers SD, Hughes M, Marsh JN, Cyrus T, Winter PM, Neubauer AM, Wickline SA, Lanza GM. International Journal of Nanomedicine. 2007; 2:515. [PubMed: 18203420]

130. Pan H, Myerson JW, Ivashyna O, Soman NR, Marsh JN, Hood JL, Lanza GM, Schlesinger PH, Wickline SA. FASEB. 2010; 24:2928.

131. Pan H, Myerson JW, Hu L, Marsh JN, Hou K, Scott MJ, Allen JS, Hu G, San Roman S, Lanza GM, Schreiber RD, Schlesinger PH, Wickline SA. FASEB. 2013; 27:255.

132. Winter PM, Caruthers SD, Yu X, Song S-K, Chen J, Miller B, Bulte JWM, Robertson JD, Gaffney PJ, Wickline SA, Lanza GM. Magnetic Resonance in Medicine. 2003; 50:411. [PubMed: 12876719]

133. Bentzon JF, Falk E. Current Opinion in Lipidology. 2010; 21:434. [PubMed: 20683327]

134. Fitzgerald KT, Holladay CA, McCarthy C, Power KA, Pandit A, Gallagher WM. Small. 2011; 7:705. [PubMed: 21319299]

135. Miteva M, Kirkbride KC, Kilchrist KV, Werfel TA, Li H, Nelson CE, Gupta MK, Giorgio TD, Duvall CL. Biomaterials. 2015; 38:97. [PubMed: 25453977]

136. Huang RB, Mocherla S, Heslinga MJ, Charoenphol P, Eniola-Adefeso O. Molecular Membrane Biology. 2010; 27:190. [PubMed: 20615080]

137. Sanz J, Fayad ZA. Nature. 2008; 451:953. [PubMed: 18288186]

138. Lund-Katz S, Liu L, Thuahnai ST, Phillips MC. Frontiers in Bioscience. 2003; 8:d1044.

[PubMed: 12700101] 


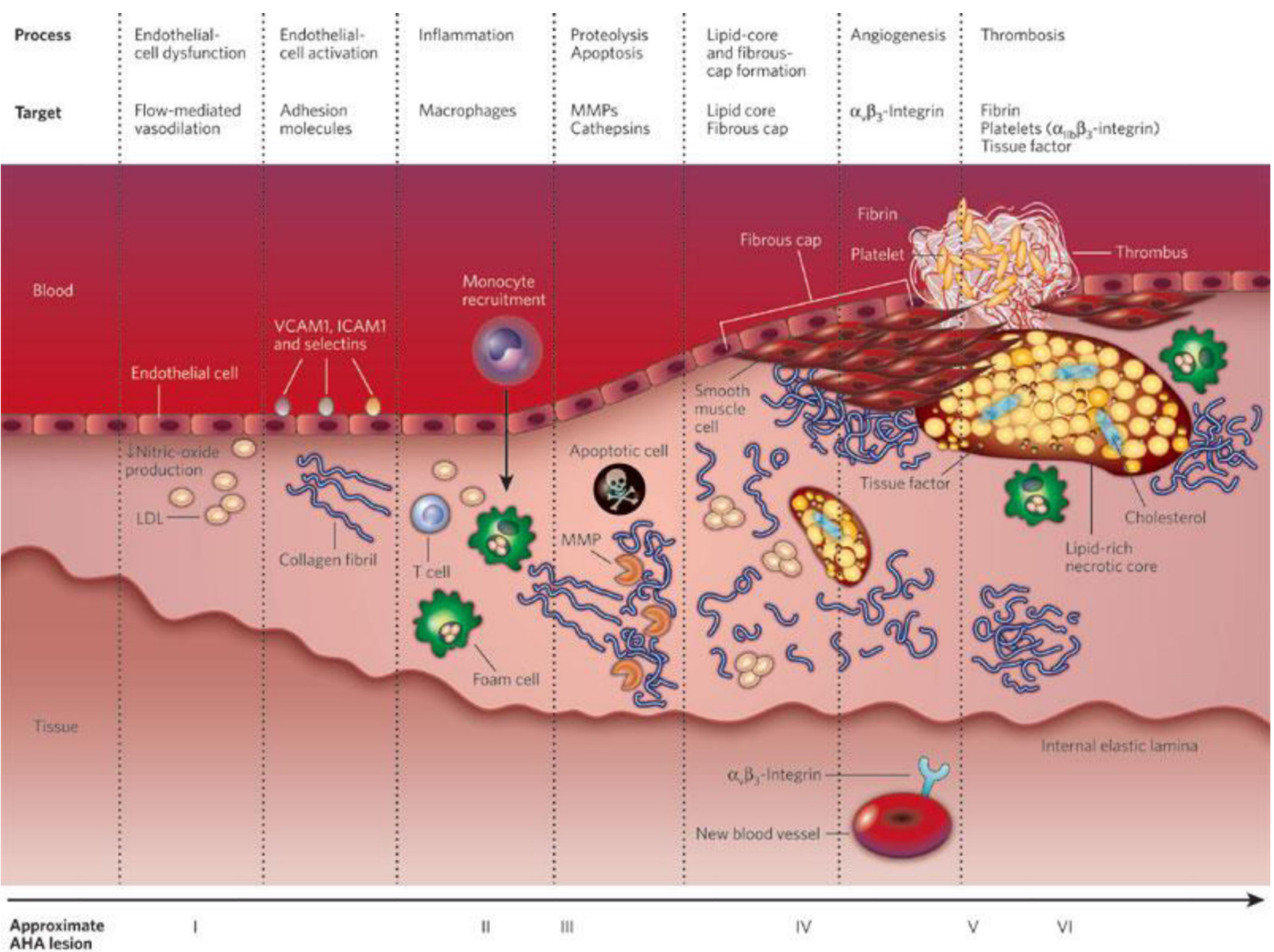

Figure 1. The progression of an atherosclerotic lesion

Development of lesion from a normal blood vessel (left) to a vessel with an atherosclerotic plaque with thrombus formation (right) ${ }^{[137]}$. 
A

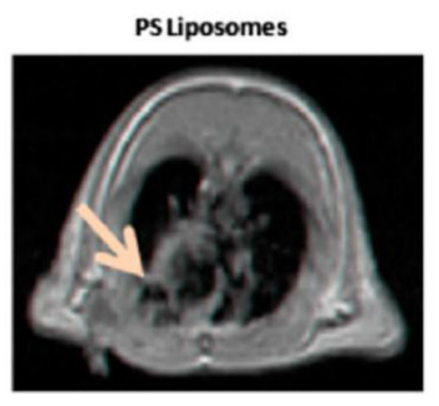

B

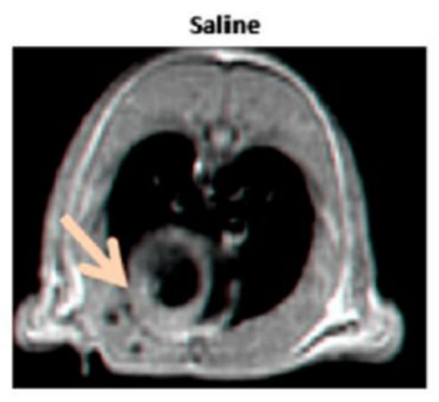

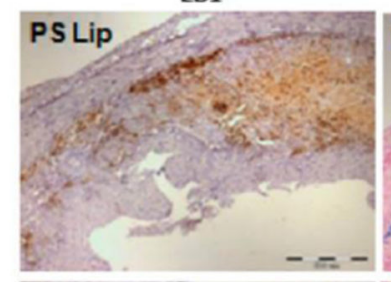
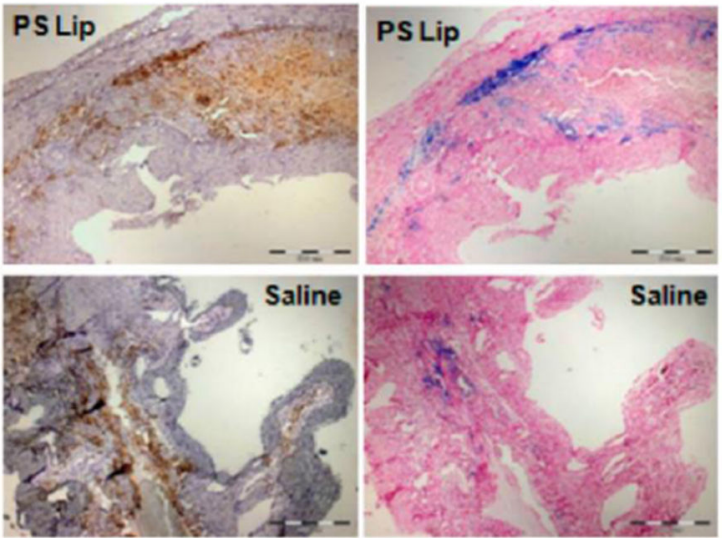

Figure 2. In vivo uptake and accumulation of PS-presenting liposomes in cardiac macrophages after intravenous administration in rats

MI was induced in rats and 48 hours later, PS-presenting liposomes entrapping iron-oxide or saline were injected through the femoral vein. Four days later, the rats were examined by MRI A) to evaluate macrophage accumulation at the infarct. The dark areas in the coronal sections represent macrophages, which have uptaken PS presenting liposomes containing the iron oxide. B) Histology/immunohistochemistry of cross-sections from hearts excised from mice treated with PS-presenting liposomes containing iron oxide overlap with macrophages upon immunostaining for ED1 (a marker for resident macrophages, brown color) and iron oxide (blue color). Scale Bar: $500 \mu \mathrm{m}^{[49]}$. 


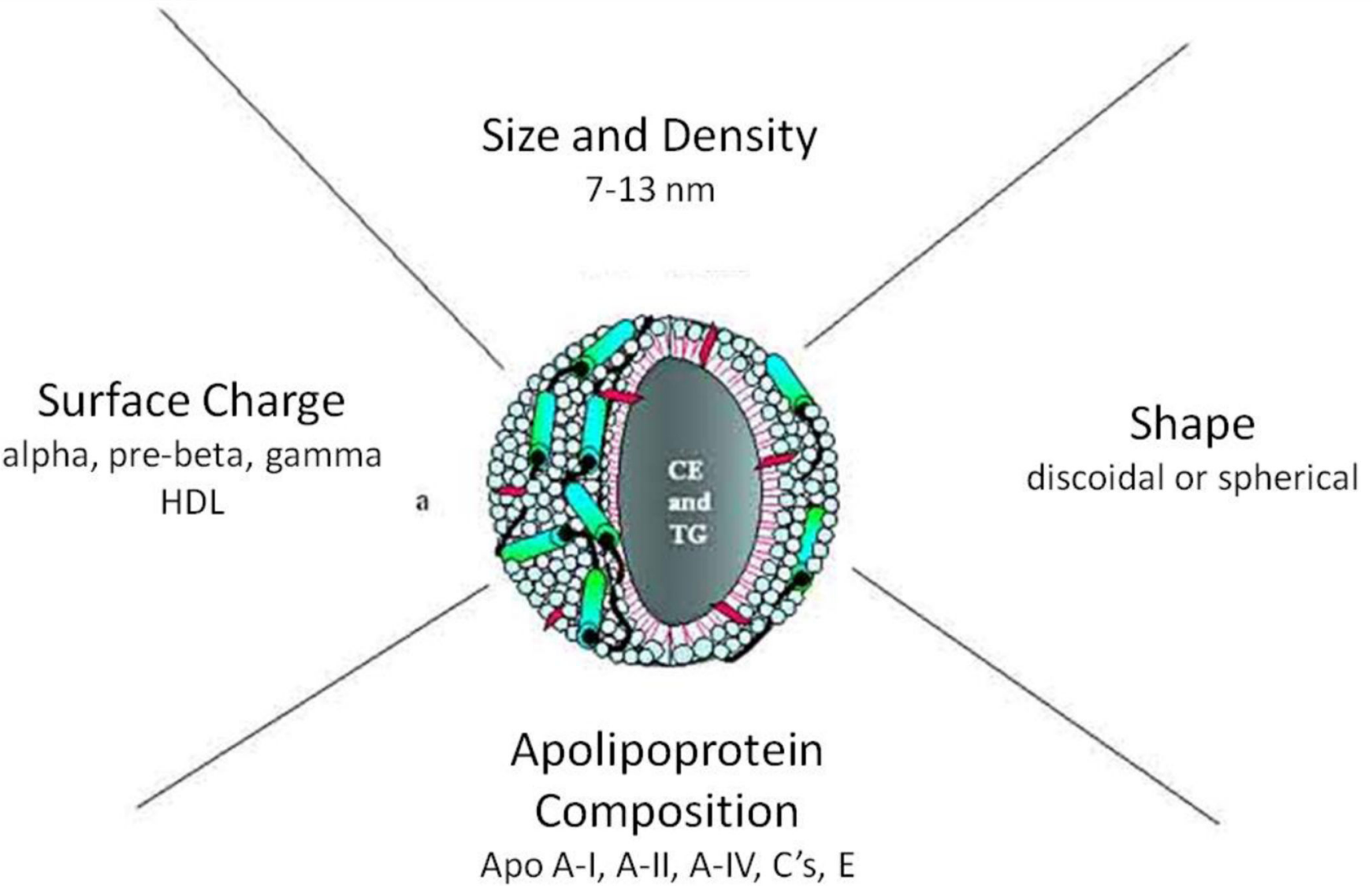

Figure 3. HDL particles are heterogeneous depending on composition Native HDLs differ in surface charge, size and density, shape, and apolipoprotein composition. CE, cholesterol; TG, triglyceride ${ }^{[138]}$. 
A

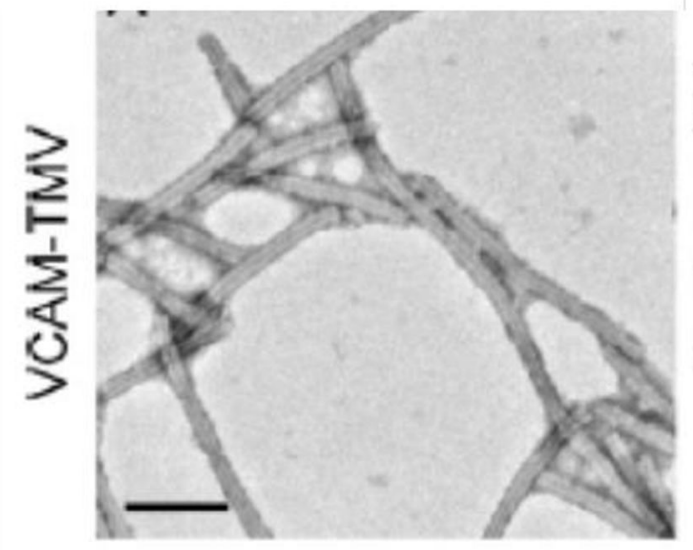

B

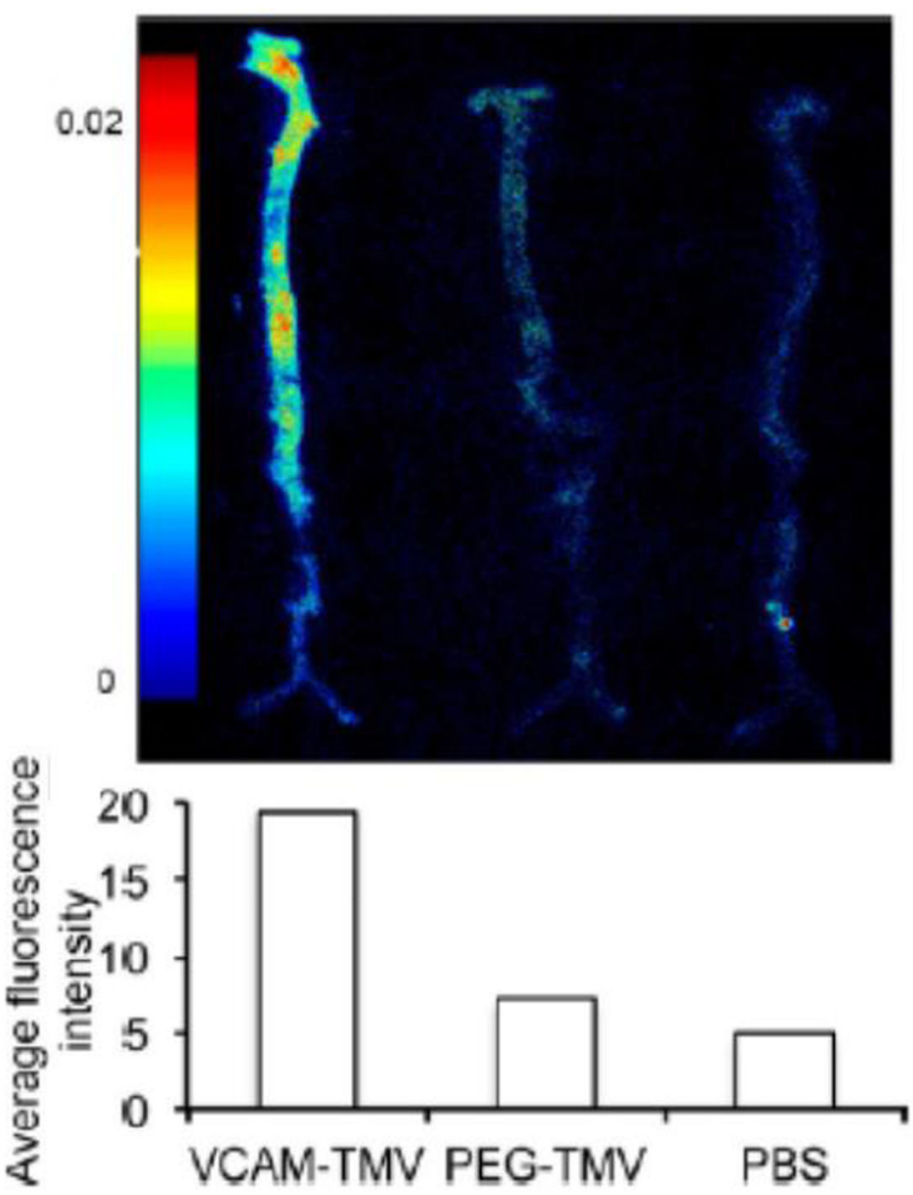

Figure 4. Tobacco mosaic virus (TMV) particles for atherosclerosis

A) Transmission electron micrographs of VCAM-TMV and PEG-TMV. B) Upon injection into the ApoE-/- mouse, VCAM-TMV particles bound to aortas with a 3-fold increase over PEG-TMV particles via ex vivo fluorescence imaging after 3 hours post-injection ${ }^{[93]}$. 


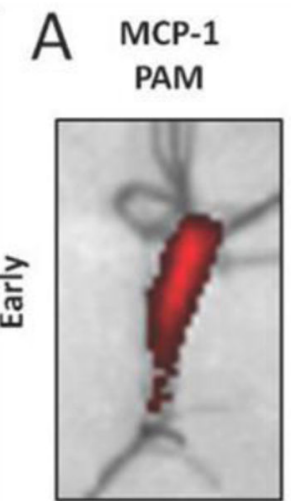

Scrambled

B
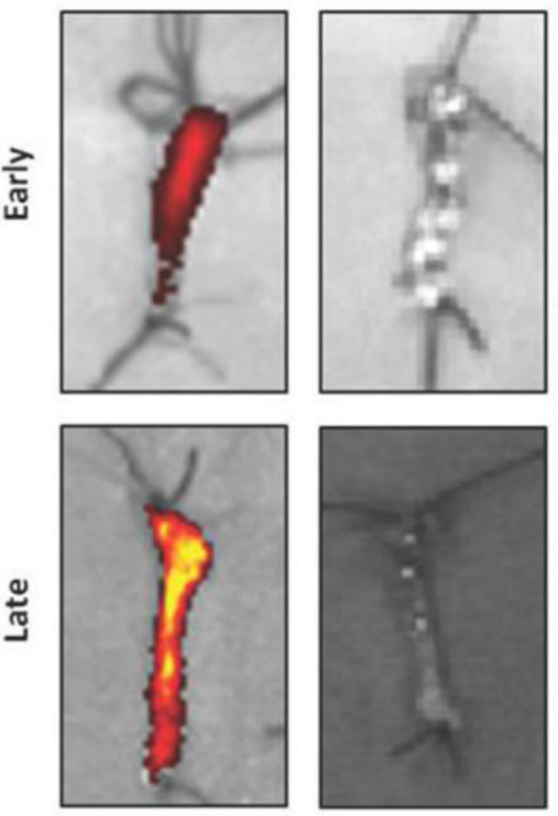

Aortic

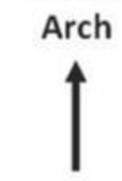

Abdominal

Aorta
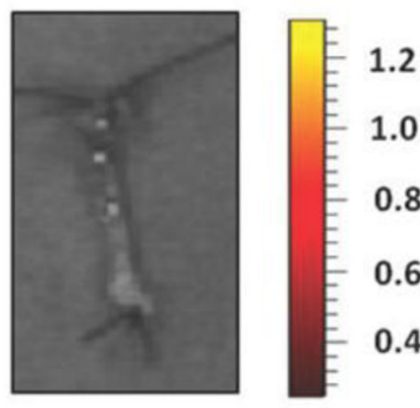

1.2

1.0

$.8 \times 10^{8}$

0.6

0.4

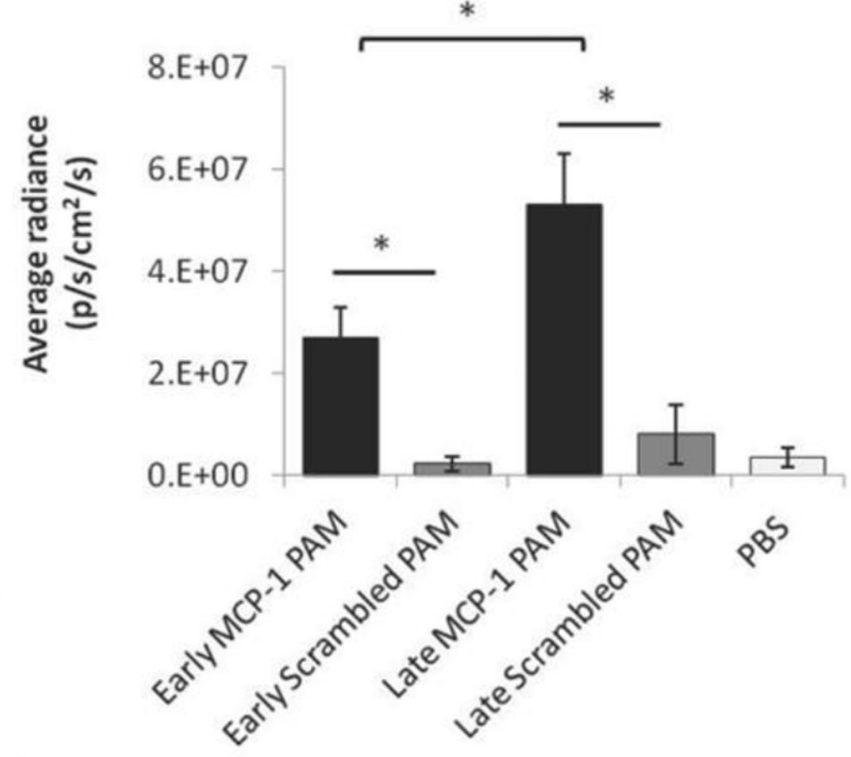

Figure 5. MCP-1 targeting peptide amphiphile micelles detect and discriminate between stages of atherosclerosis

After 24 hours post-injection into early or late-stage atherosclerotic ApoE-/- mice, MCP-1 peptide amphiphile micelles localize to the aorta vs. scrambled peptide amphiphile controls, and can be distinguished both A) qualitatively and B) quantitatively using optical imaging $[106]$. 

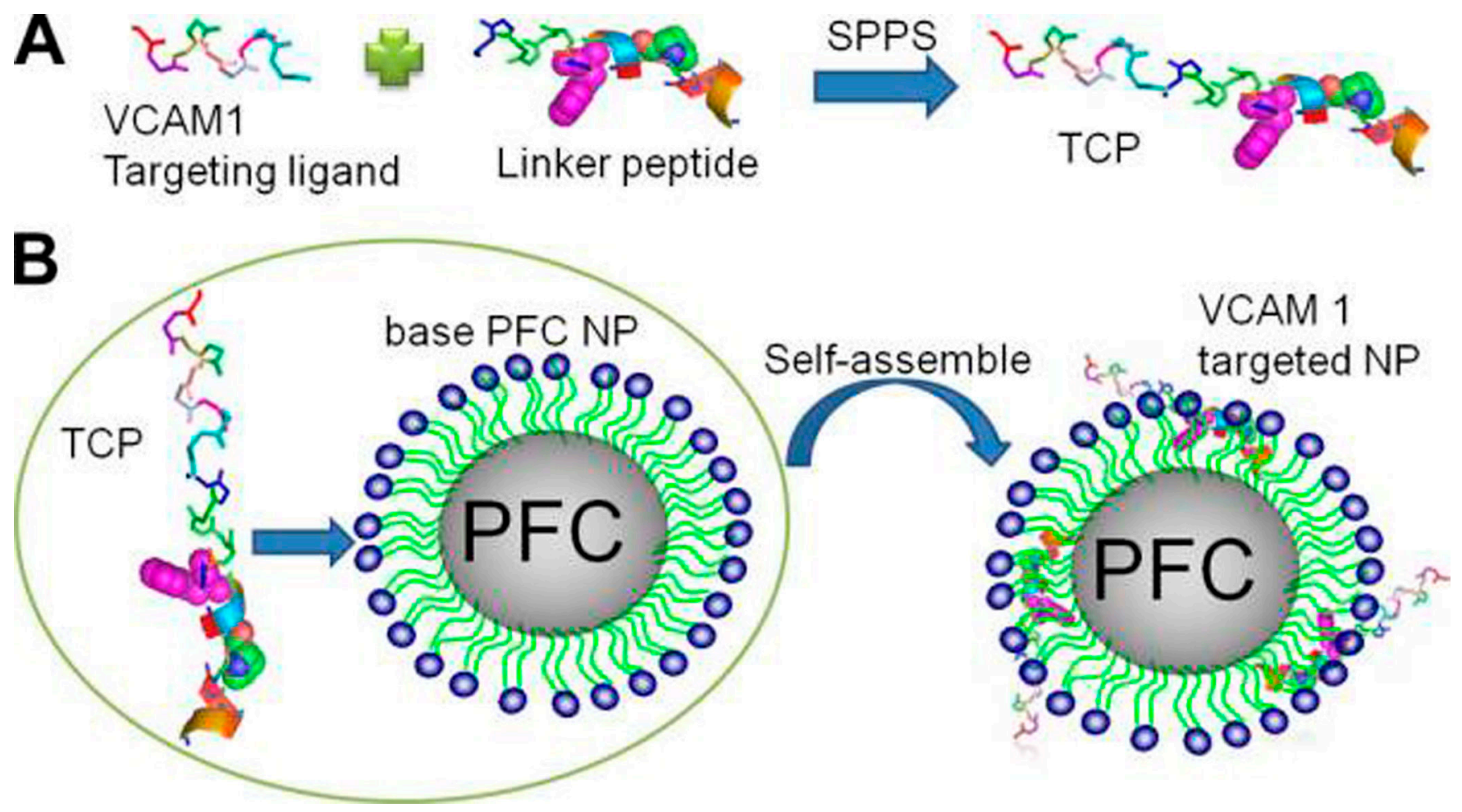

Figure 6. Schematic of PFC nanoparticle functionalization with VCAM-1 targeting peptides A) VCAM-1 targeting peptides were first conjugated to a linker peptide before B) mixing with PFC nanoparticles to develop targeting nanoparticles ${ }^{[131]}$ 